\title{
Modulation of olfactory sensitivity and glucose-sensing by the feeding state in obese Zucker rats
}

\author{
Pascaline Aimé ${ }^{1 \dagger}$, Brigitte Palouzier-Paulignan ${ }^{1}$, Rita Salem ${ }^{1}$, Dolly Al Koborssy ${ }^{1}$, Samuel Garcia ${ }^{1}$, \\ Claude Duchamp ${ }^{2}$, Caroline Romestaing ${ }^{2}$ and A. Karyn Julliard ${ }^{1 *}$
}

Team "Olfaction: From Coding to Memory," Lyon Neuroscience Center, INSERM U1028-CNRS 5292- Université Lyon1, Lyon, France

${ }^{2}$ Laboratoire d'Ecologie des Hydrosystèmes Naturels et Anthropisés, CNRS 5023, Villeurbanne, France

\section{Edited by:}

Donald A. Wilson, New York

University School of Medicine, USA

Reviewed by:

Daniel W. Wesson, Case Western

Reserve University, USA

Edgar Soria, Institut National de la

Santé et de la Recherche Médicale,

France

${ }^{*}$ Correspondence:

A. Karyn Julliard, Team "Olfaction:

From Coding to Memory," Lyon

Neuroscience Center, INSERM

U1028-CNRS 5292- Université

Lyon1, 50 Av. Tony Garnier F-69366

Lyon Cedex 07, France

e-mail: karyn.julliard@univ-lyon1.fr

${ }^{\dagger}$ Present address:

Department of Pathology and Cell

Biology, Columbia University

Medical Center, New York, NY

10032, USA
The Zucker fa/fa rat has been widely used as an animal model to study obesity, since it recapitulates most of its behavioral and metabolic dysfunctions, such as hyperphagia, hyperglycemia and insulin resistance. Although it is well established that olfaction is under nutritional and hormonal influences, little is known about the impact of metabolic dysfunctions on olfactory performances and glucose-sensing in the olfactory system of the obese Zucker rat. In the present study, using a behavioral paradigm based on a conditioned olfactory aversion, we have shown that both obese and lean Zucker rats have a better olfactory sensitivity when they are fasted than when they are satiated. Interestingly, the obese Zucker rats displayed a higher olfactory sensitivity than their lean controls. By investigating the molecular mechanisms involved in glucose-sensing in the olfactory system, we demonstrated that sodium-coupled glucose transporters 1 (SGLT1) and insulin dependent glucose transporters 4 (GLUT4) are both expressed in the olfactory bulb (OB). By comparing the expression of GLUT4 and SGLT1 in OB of obese and lean Zucker rats, we found that only SGLT1 is regulated in genotype-dependent manner. Next, we used glucose oxidase biosensors to simultaneously measure in vivo the extracellular fluid glucose concentrations ([Gluc $]_{\mathrm{ECF}}$ ) in the $\mathrm{OB}$ and the cortex. Under metabolic steady state, we have determined that the OB contained twice the amount of glucose found in the cortex. In both regions, the [Gluc $]_{E C F}$ was 2 fold higher in obese rats compared to their lean controls. Under induced dynamic glycemia conditions, insulin injection produced a greater decrease of [Gluc] $]_{E C F}$ in the OB than in the cortex. Glucose injection did not affect OB [Gluc] $]_{E C F}$ in Zucker fa/fa rats. In conclusion, these results emphasize the importance of glucose for the $O B$ network function and provide strong arguments towards establishing the OB glucose-sensing as a key factor for sensory olfactory processing.

Keywords: olfactory sensitivity, obesity, olfactory bulb, glucose-sensing, GLUT4, SGLT1, extracellular glucose concentration, feeding state

\section{INTRODUCTION}

The Zucker "fatty" rat is a model of genetic obesity. The mutation, named fatty or $f a$, is autosomic recessive, therefore while $f a / f a$ rats become obese at 3-5 weeks of age, the heterozygous $\mathrm{fa} / \mathrm{+}$ rats remain phenotypically normal. The $f a$ mutation affects the extracellular part of the leptin receptor which demonstrates a weaker affinity for leptin and an altered signal transduction (White and Martin, 1997; Yamashita et al., 1997). Leptin receptors are present in several hypothalamic nuclei playing an important role in the central regulation of energy balance (Tartaglia et al., 1995; Mercer et al., 1996; Fei et al., 1997; Shioda et al., 1998; Burguera et al., 2000). Because leptin cannot exert its anorectic action in Zucker $f a / f a$ rats, these animals develop a marked hyperphagia during the first weeks of life (Vasselli et al., 1980). Consequently, the Zucker fa/fa rats exhibit a severe obese phenotype, highly similar to the human obese syndrome (Guerre-Millo, 1997; Beck, 2000). Zucker fa/fa rats display many metabolic and hormonal defects including hyperleptinemia, hyperinsulinemia, mild to moderate hyperglycemia, glucose intolerance as well as peripheral and central insulin resistance (Zucker and Antoniades, 1972; Bray, 1977; Martin et al., 1978; Ikeda et al., 1986; Pénicaud et al., 1987; Zarjevski et al., 1992; Apweiler and Freund, 1993; Guerre-Millo, 1997; Beck, 2000). As a consequence of the leptin receptor gene mutation, in the obese Zucker rats, intracerebroventricular (ICV), injections of insulin or of non-metabolized 2-deoxy-D-glucose do not change food intake in contrast these injections induce hypo- or hyper-phagia, respectively in lean Zucker rats (Ikeda et al., 1980, 1986). The absence of behavioral response to insulin and glucose ICV injections in obese Zucker rats is partly due to an impairment of hypothalamic glucose-sensing neurons. These neurons cannot adapt their firing to fluctuations of interstitial glucose concentration and cannot take part in the regulation of feeding behavior according to the metabolic needs of the organism (Rowe et al., 1996; Spanswick et al., 1997, 2000; Colombani 
et al., 2009). Among the molecules involved in glucose-sensing, the mRNA expression of glucokinase, a glucose metabolizing enzyme and of GLUT2, a glucose transporter is altered in the hypothalamus of $f a / f a$ Zucker rats (Bogacka et al., 2004). Moreover, the regional brain glucose utilization is modified in obese Zuckers, compared to lean controls (Tsujii et al., 1988; MarfaingJallat et al., 1992; Doyle et al., 1993). All together these findings converge to the conclusion that, at least in brain areas wellknown to be involved in the control of food intake, the neuronal glucose sensitivity is largely impaired in hyperphagic $f a / f a$ Zucker rats.

Food consumption is regulated by sensory modalities among which olfaction takes an important part. In turn, olfactory sensitivity is modulated by feeding state (Aimé et al., 2007) because normal-weight Wistar rats demonstrate a better olfactory sensitivity when they are fasted than when they are satiated (Aimé et al., 2007). Moreover, ICV administrations of leptin or insulin, two anorectic hormones, decrease the olfactory sensitivity of fasted rats to the level of satiated ones (Aimé et al., 2007; Julliard et al., 2007). Conversely, central infusions of orexin A or ghrelin, two orexigenic peptides, increase the olfactory sensitivity of satiated rats to the level of fasted ones (Julliard et al., 2007; Tong et al., 2011). These converging evidences demonstrate that the olfactory bulb (OB), the first central structure responsible for the olfactory information processing, is targeted by signals (orexin A, ghrelin, leptin, insulin, NPY and CCK) involved in the regulation of energy balance (Palouzier-Paulignan et al., 2012). In addition to the hormones involved in food intake regulation, a large body of evidence indicates that the olfactory system is also sensitive to blood-borne nutrients. Two neuronal markers of glucose sensitivity, insulin-dependent glucose transporter type 4 (GLUT4) and sodium glucose co-transporter type 1 (SGLT1), are found in the olfactory system (El Messari et al., 1998). Recent patch clamp studies have shown that mitral cells change their firing rate in response to changes in glucose concentration, identifying these neurons as glucose sensors (Tucker et al., 2010, 2013) and also to changes in insulin concentration (Fadool et al., 2000; Kuczewski et al., 2014).

Given the extreme metabolic features of the obese Zucker $\mathrm{fa} / \mathrm{fa}$ rats described above and the recent studies demonstrating a strong effect of the peripheral and central signals involved in the regulation of energy balance on olfactory processing and glucose sensitivity in the olfactory system, the present study was conducted to (i) test whether the obese Zucker $f a / f a$ rats display a normal regulation of the olfactory sensitivity by the feeding states; (ii) compare the olfactory sensitivity of lean Zucker $\mathrm{fa} /+$ rats and obese Zucker $f a / f a$ rats; and (iii) investigate whether the glucose concentration, GLUT4 and SGLT1 expression in the OB might be altered in the genetically obese and moderately diabetic Zucker $\mathrm{fa} / \mathrm{fa}$ rat.

\section{MATERIALS AND METHODS ANIMALS PREPARATION}

Male lean $(f a /+; n=24)$ and obese $(f a / f a ; n=24)$ Zucker rats, were purchased from Charles River Laboratories. The animals were handled (5 min/day) and weighed daily. On arrival, they were 7-8 weeks old and weighed $299 \pm 7.2 \mathrm{~g}(\mathrm{fa} /+)$ and $344 \pm$
$11.8 \mathrm{~g}(\mathrm{fa} / \mathrm{fa})$. Experiments were carried out in accordance with the European Community Council Directive of November 24th, 1986 (86/609/EEC) for the care and use of laboratory animals. The Animals were housed in groups ( 4 rats) in plexiglas chambers at constant ambient temperature and relative humidity $(22 \pm$ $0.5^{\circ} \mathrm{C}$ and $\left.50 \pm 5 \%\right)$. They were acclimated to a $12 \mathrm{~h}$ light $/ 12 \mathrm{~h}$ dark inverted cycle, with the light turned on at Zeitgeber time zero (ZT0). Upon arrival, the rats were given ad libitum access to food (chow pellets, Harlan, France) and water. 2-3 weeks prior to experimental procedure, the rats were gradually habituated to a $20 \mathrm{~h}$ /day food restriction (FR) schedule in which they had access to food during dark phase only, from ZT16 to ZT20. Since daily fluctuations in glycemia and insulin levels are cued by food intake (Kaul and Berdanier, 1975; Sitren and Stevenson, 1978), a single daily meal was imposed to synchronize the circadian variations of glycemia and insulin secretion among the animal cohort. Animals were handled ( $5 \mathrm{~min} /$ day) and weighed daily to assess their adaptation to FR. The daily amount of food consumed was measured for lean and obese rats in order to avoid weight loss and allow stabilization or a small gain of body weight. The daily food distribution schedule was performed by an automatic food distribution system (homemade) piloted by a computer using Matlab software.

\section{BEHAVIORAL PROCEDURE}

The behavioral test was performed as previously described (Aimé et al., 2007, 2012; Julliard et al., 2007; Tong et al., 2011) with minor modifications, as follow. 12 Zucker $f a /+$ and 12 Zucker $f a / f a$ rats were submitted to the behavioral procedure. The conditioned odor aversion (COA) protocol consisted in pairing the ingestion of an odorized drink with an intraperitoneal (i.p.) injection of lithium chloride ( $\mathrm{LiCl}$, Sigma-Aldrich). This procedure induces a robust aversion to the odor diluted in the drinking solution. The olfactory sensitivity is then tested by measuring the aversive behavioral response to a range of lower odor concentrations. In order to induce drink intake during behavioral test, in addition to the FR, rats were placed on a $23 \mathrm{~h}$ water restriction schedule that started 1 week prior behavioral procedure and was maintained throughout the behavioral protocol. Animals had access to water for $1 \mathrm{~h}$, during the daily food distribution. Experiments consisted of two 5-min daily sessions occurring at $9 \mathrm{~h}$ intervals. The first session ( $\mathrm{S} 1$ ) started at the beginning of the dark phase (ZT13; after $17 \mathrm{~h}$ of fasting) and the second (S2) started during the dark phase, during the postprandial phase (ZT22, $2 \mathrm{~h}$ after the end of the meal; Figure 1A). This paradigm allowed each animal to be successively tested in two steady physiological states, fasted (S1) and satiated (S2) each day of the behavioral test. In a first period, corresponding to the habituation, rats were trained for 2 days to lick pure water at the two drinking tubes of the experimental cage (not shown). The experimental set-up allowed the recording of licking behavior using a two-tube device described elsewhere (Aimé et al., 2007, 2012; Julliard et al., 2007). During the next 2 days (Figure 1B: D1 to D2, Aversion acquisition), rats only had access to water odorized with isoamyl-acetate (ISO, SigmaAldrich). An ISO consumption of more than $0.5 \mathrm{~mL}$ was paired $15 \mathrm{~min}$ later, with an i.p. injection of $\mathrm{LiCl}(10 \mathrm{~mL} / \mathrm{kg}$ at $0.15 \mathrm{M})$ to induce gastric malaise and establish a COA to ISO. ISO was used 


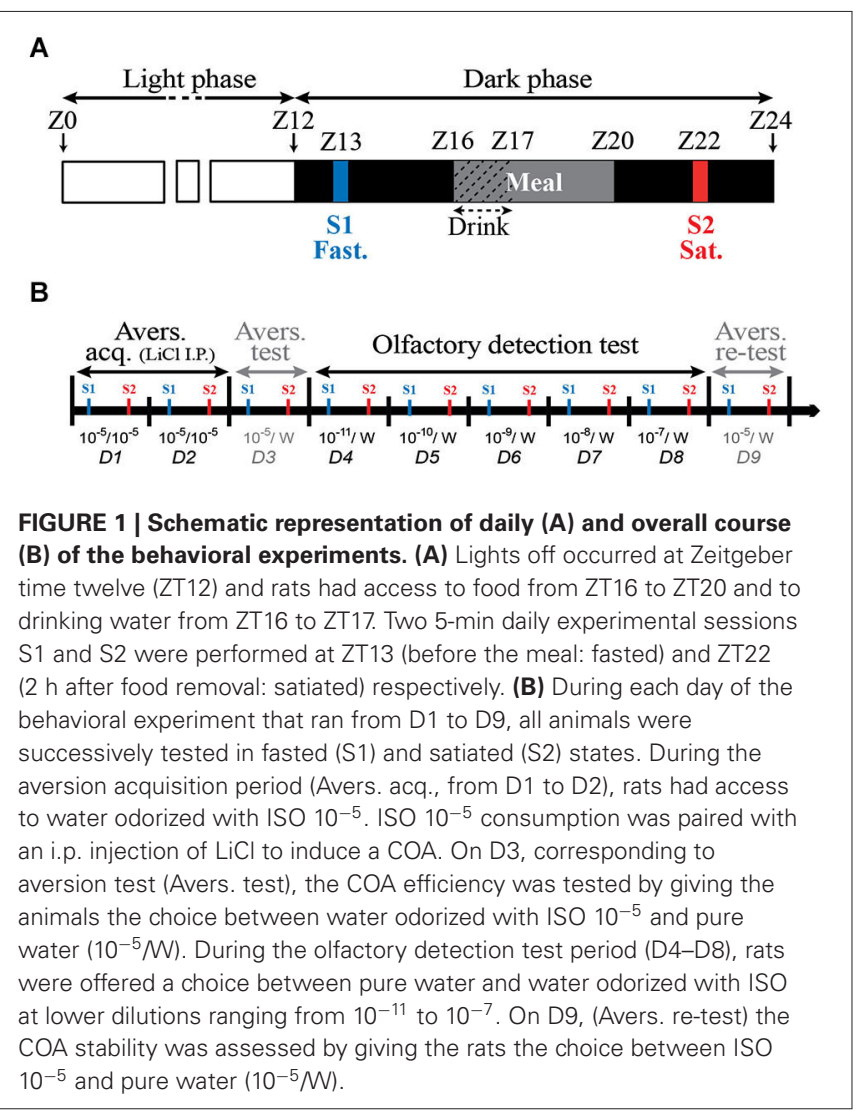

at the dilution of $10^{-5}$, for which the solution has a strong odor but has been shown to be tasteless (Slotnick et al., 1997). Thus at this dilution, the rats can only identify ISO via the olfactory pathways. Depending on individuals, 1-4 conditioning sessions (S1 and S2 for each 2 days) were required for the animal to develop a strong aversion to ISO $10^{-5}$. On D3 (Figure 1B: Aversion test), the COA efficiency was tested by giving the animals the choice between pure water and water odorized with ISO $10^{-5}$. Then the animals were submitted to the olfactory detection test (Figure 1B: D4 to D8). For this, rats were offered a choice between pure water and water odorized with ISO at lower dilutions. At the beginning of each experimental session of the olfactory detection test, the animals were placed under the odorized water tube. Rat olfactory detection for ISO was thus assessed using a forced-choice task, and not by using a simple choice task, since the thirsty rats were forced to smell the odorized tube first. This procedure was chosen to avoid the possibility that the rats, highly motivated by thirst, would go by chance to the pure water tube first, drink only water, and not sample the ISO tube. The conditioned aversion was then tested using drinking solution with ISO dilutions ranging from $10^{-11}$ to $10^{-7}$. Each given odor concentration was presented to the same rat in fasted (ZT13) and later in satiated (ZT22: i.e., $2 \mathrm{~h}$ after the food intake end) status. On D9 (Figure 1B: Aversion re-test), COA stability was assessed by giving the rats the choice between the standard ISO solution $\left(10^{-5}\right)$ and pure water.

For each concentration, an olfactory detection index was calculated. It corresponds to the proportion of the number of licks at the pure water tube normalized to the total number of licks (odorized + pure water) in the experimental device. When rats perceived ISO in the drinking solution (and consequently avoided it), they licked more pure water during the experimental session, resulting in a higher olfactory detection index. In addition, the number of licks during the first ISO consumption (first licking burst) in the experimental device was recorded. This data allowed us to accurately measure the delay necessary for the animals to be able to detect the aversive ISO diluted in the drinking solution. Data from rats starting the experimental session by drinking at the pure water tube (maximum 2 rats out of 12 per ISO dilution) was excluded from this analysis. In order to exclude a potential bias induced by the number of conditioning sessions on the strength of the COA, a Pearson correlation test was performed between the number of $\mathrm{LiCl}$ injections and the olfactory detection index for each animal, for each nutritional status and for each ISO concentration tested. No correlation was observed $(P>0.05)$ for both $f a / f a$ and $f a /+$ rats. The number of lick during the first burst, the end of the licking burst and the total number of licks at each tube during the experimental sessions were assessed and analyzed using SciPy and MySql database software (Open Source Licenses). A licking burst was defined by a train of high frequency licks $(7-10 \mathrm{~Hz})$ and the end of licking burst was determined when the last lick was followed by a period of inactivity lasting at least $1 \mathrm{~s}$.

\section{PHYSIOLOGICAL MEASUREMENTS}

To characterize the two metabolic steady states of the fasted and satiated rats, the concentrations of plasma glucose, plasma insulin, and $\mathrm{OB}$ insulin were measured. Peripheral blood glucose level was determined by sampling $5 \mu \mathrm{L}$ of tail blood $1 \mathrm{~h}$ before and $2 \mathrm{~h}$ after food intake for fasted and satiated rats respectively. Glucose levels were monitored with a glucose meter (Accu-Chek ${ }^{\circledR}$ Roche, Mannheim, Allemagne/Performa). Plasma and OB insulin levels were measured in fasted (ZT12; $n=6$ for each genotype) or in satiated (ZT22; $n=6$ for each genotype) state. At the end of the behavioral procedure, rats were deeply anesthetized using an i.p. injection of ketamine (Imalgene, $80 \mathrm{mg} / \mathrm{kg}$ ) and xylazine (Rompun, $10 \mathrm{mg} / \mathrm{kg}$ ), then rats were euthanized, and their OBs immediately frozen in liquid nitrogen. Trunk blood was collected in heparinized tubes, and the plasma fraction was separated by centrifugation at $2000 \mathrm{~g}$ for $5 \mathrm{~min}$. Insulin was extracted from one $\mathrm{OB}$ per rat according to the procedure of Baskin et al. (1983) and the other OB was saved for Western blotting. To determine the influence of the yield of the insulin extraction procedure, samples with known amounts of insulin, were submitted to the same protocol. The mean extraction output was found to be $\sim 40 \%$. Plasma and $\mathrm{OB}$ insulin levels were determined using a solid-phase, two-site enzyme immunoassay following the manufacturer's protocol (Mercodia Ultrasensitive Rat Insulin ELISA).

\section{WESTERN BLOT ANALYSIS}

One of two OB removed from rats previously used for behavioral procedure was homogenized in ice-cold homogenization buffer (Tris $5 \mathrm{mM}$, EGTA $2 \mathrm{mM}, \mathrm{pH}$ 7.4) supplemented with an antiprotease cocktail (SIGMA P8340, $10 \mu \mathrm{l}$ per mg tissue). Western Blot analysis was performed with $\mathrm{OB}$ homogenates from rats 
euthanized either in fasted (ZT12; $n=4$ for each genotype) or in satiated (ZT22; $n=4$ for each genotype) state. Protein concentrations were determined by BCA assay according to the manufacturer's recommendation (PIERCE \#23225). $100 \mu \mathrm{g}$ of proteins were loaded into 7.5\% SDS-polyacrylamide gels (SDSPAGE) and electrophoresed for $1.5 \mathrm{~h}$ at $110 \mathrm{~V}$. Proteins were then electro-transferred for $1 \mathrm{~h}$ at $300 \mathrm{~mA}$ onto a PVDF membrane. Membranes were blocked with 5\% milk in TBS containing 0.05\% of Tween 20 and incubated overnight with polyclonal antibodies directed against GLUT4 (Millipore 07-1404; dilution 1:250), or SGLT1 (Santa Cruz sc-20584; dilution 1:1000). Equal loading was verified using Ponceau red stain, and by detection of the control protein $\beta$-actin (Sigma; diultion 1:8000). Membranes were washed in $0.05 \%$ Tween-PBS buffer and incubated with horseradish peroxidase-conjugated secondary antibody (dilution 1:10000). Signals were detected using the enhanced chemiluminescence detection system (Pierce \#32106). Immunoblots were scanned using a desktop scanner (Epson Perfection V350) and Adobe Photoshop. Band intensities were determined using Scion Image (Scion Corporation, USA).

\section{IMMUNOSTAINING}

Animals were anesthetized (using the same protocol as described previously for ELISA and Western Blot analysis) and euthanized in the fasted (ZT12; $n=4$ for each genotype) or in the satiated (ZT22; $n=4$ for each genotype) state. Immunofluorescence was performed on fresh frozen brain samples by using a modification of a published method (Julliard and Hartmann, 1998). Brain cryosections were pre-incubated for $15 \mathrm{~min}$ with a blocking buffer containing $0.1 \mathrm{M}$ phosphate buffer saline (PBS, $\mathrm{pH}=7.4), 3 \%$ bovine serum albumin (BSA, Sigma-Aldrich) and $5 \%$ normal serum from the host species of the antibodies. The sections were then incubated overnight at $4^{\circ} \mathrm{C}$ with primary antibodies for SGLT-1 (R-16) (1:100; Santa Cruz Biochemicals, Santa Cruz, CA). A GLUT4 mouse antibody was used which recognizes an epitope in the cytoplasmic portion of GLUT4 [1F8] (1:100 abCam). The sections were washed with $0.1 \mathrm{M} \mathrm{PBS/3 \%}$ BSA and incubated for $1 \mathrm{~h}$ at room temperature with anti-rabbit IgG, anti-mouse IgG, or anti-goat secondary antisera coupled to Alexa 488 (1:100), Cy3 (1:200; Jackson Immunoresearch), or Cy5 (1/100; Jackson Immunoresearch) respectively. After the final wash with PBS, slides were mounted with Vectashield mounting medium containing DAPI for nuclear staining (Vector Laboratories). Images were acquired using a Zeiss Apotome epifluorescence microscope equipped with a digital camera and Axiovision software.

\section{BIOPROBE MEASUREMENTS OF EXTRACELLULAR GLUCOSE Surgical procedure}

Eight Zucker $\mathrm{fa} /+$ and eight Zucker $\mathrm{fa} / \mathrm{fa}$ rats were used during measurements of extracellular glucose in the brain. Rats in the fasted (ZT12, $n=4$ for each genotype) or satiated (ZT22, $n=4$ for each genotype) state were anesthetized with urethane $(1.5 \mathrm{mg} / \mathrm{kg}$, i.p.). The anesthetized animals were placed in a stereotaxic apparatus and kept on a heating pad, and additional doses of urethane were supplied as needed. The surgical procedure consisted of drilling three burr holes into the skull to expose the lateral region of each $\mathrm{OB}$ and the somatosensory cortex as a control brain area. The first glucose-oxidase biosensor was implanted into the lateral part of one $\mathrm{OB}$, within or close to the glomerular layer (GL; coordinates: AP $+6.5 \mathrm{~mm}$ from Bregma, M/L $-2.3 \mathrm{~mm}$ and $\mathrm{D} / \mathrm{V}-1.0 \mathrm{~mm}$ from dura, Figure 2). The second glucoseoxidase biosensor was inserted in the controlateral somatosensory cortex (coordinates: AP $-3.5 \mathrm{~mm}$ from Bregma, $\mathrm{M} / \mathrm{L}+2.3$ and $\mathrm{D} / \mathrm{V}-2.3 \mathrm{~mm}$ from dura). A control BSA sensor was implanted in the other $\mathrm{OB}$ to measure nonspecific variations in oxidation current (coordinates similar to glucose biosensors implanted in $\mathrm{OB}$, Figure 2). A reference electrode $(\mathrm{Ag} / \mathrm{AgCl})$ was placed into neck muscles during in vivo recordings.

\section{Preparation of electrochemical sensors}

The glucose biosensor uses glucose oxidase and amperometric detection of hydrogen peroxide (Vasylieva et al., 2011). The tip of the probe was coated with glucose oxidase only on 100-150 $\mu \mathrm{m}$ in length (Vasylieva et al., 2011) to target mainly the GL, which thickness is ranging from 100 to $300 \mu \mathrm{m}$. Glucose oxidase metabolizes glucose in the extracellular fluid. An oxidation current is thus generated and measured using Neurolabscope software. Each biosensor was connected to a potentiostat, which sent readings of the current generated by glucose in extracellular fluid to a computer. Glucose biosensors have been shown previously to have a range of $0-10 \mathrm{mM}$ with in vitro sensitivity of $1.6 \pm 0.4 \mathrm{nA} / \mathrm{mM}$ (mean \pm SEM). To confirm the accuracy of the biosensors, prior to implantation and immediately following testing, biosensor probe were placed in $0.1 \mathrm{M}$ PBS, connected to the potentiostat, and readings were allowed to stabilize (generally stable within 15-30 $\mathrm{min})$.

\section{Selectivity and calibration of biosensors}

Before the experiments all biosensors were tested for detection of serotonin (5-HT, $20 \mu \mathrm{M}$ in PBS; Sigma) and $\mathrm{H}_{2} \mathrm{O}_{2}(1 \mu \mathrm{M}$ in PBS). Only electrodes exhibiting less than $1.2 \mu \mathrm{A} \cdot \mathrm{mM}^{-1} \mathrm{~cm}^{-2}$ response for 5-HT were included in the study. In vitro calibrations were performed in standard PBS (0.01 M, pH 7.4) and solutions were maintained at a temperature of $36.5^{\circ} \mathrm{C}$, comparable to the brain of an anesthetized rat (Zhu et al., 2004). The reference electrode $(\mathrm{Ag} / \mathrm{AgCl})$ was placed directly in the solution. After a stable baseline reading, the glucose sensors were calibrated using glucose solutions at different concentrations $(0 ; 0.5 ; 1 ; 1.25$ and $1.5 \mathrm{mM}$ ) to establish the $\mathrm{nA} / \mathrm{mM}$ ratio. The applied voltage for amperometric studies was $+500 \mathrm{mV}$. Biosensors were calibrated before and after each real-time in vivo experiment to ensure the sensitivity remained stable. Quantitative assessments of brain glucose concentrations were obtained by subtracting the nonspecific current of the control biosensor (BSA) from the output of the glucose biosensors.

\section{Real-time measurements in vivo}

To compare glucose level variations in the $\mathrm{OB}$ and the cortex to the peripheral glucose concentrations, $5 \mu \mathrm{l}$ blood samples were collected from the femoral artery at the beginning of the surgery and then every $10 \mathrm{~min}$ thereafter. Glucose readings were performed with a glucose meter (Accu-Chek ${ }^{\circledR}$ Roche, Mannheim, Allemagne/Performa). 


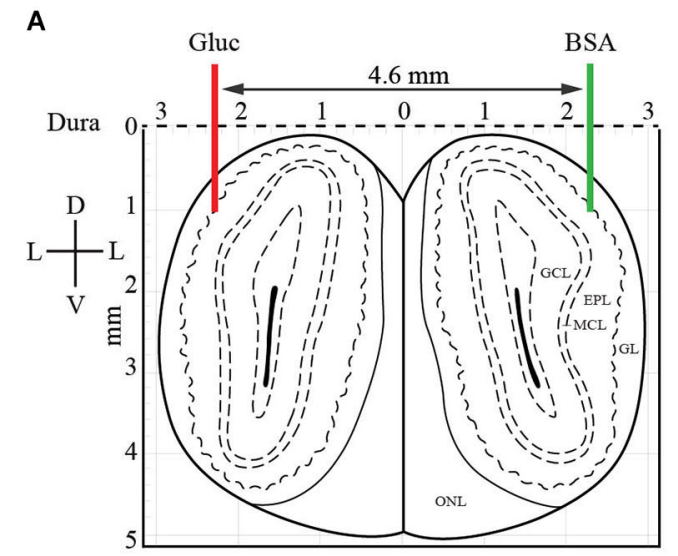

B

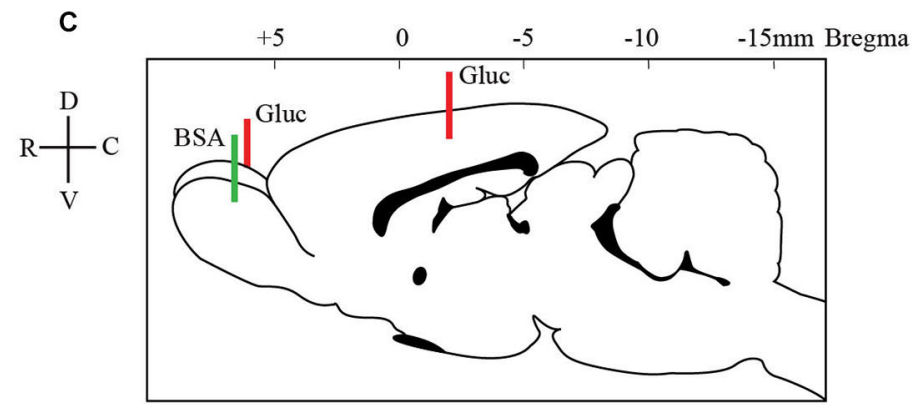

FIGURE 2 | Localization of glucose-oxidase biosensors (red) and control BSA sensor (green) electrodes in $\mathrm{OB}(\mathrm{A}, \mathrm{C})$ and somatosensory cortex (B, C). At the OB level (A), two electrodes were implanted symmetrically (coordinates: $\mathrm{AP}+6.5 \mathrm{~mm}$ from Bregma, $\mathrm{M} / \mathrm{L}-2.3 \mathrm{~mm}$ and $\mathrm{D} / \mathrm{N}-1.0 \mathrm{~mm}$ from dura). A glucose-oxidase biosensor (Gluc, red line) was positioned in one bulb and a control BSA sensor (BSA, green line) in the other bulb. The latter was set to measure nonspecific variations in oxidation current. In the somatosensory cortex (B), contralateral to the OB glucose sensor, the second glucose-oxidase biosensor was inserted (coordinates: AP $-3.5 \mathrm{~mm}$ from Bregma, $M / L+2.3$ and $\mathrm{D} N-2.3 \mathrm{~mm}$ from dura). The coronal drawings are from the Paxinos and Watson (2007) atlas, plates 1 and 27 (EPL: external plexiform layer, GCL: granular cell layer, GL: glomerular layer, MCL: mitral cell layer).
Measurements of extracellular glucose in rat brains started $1 \mathrm{~h}$ after the implantation of the electrodes, to allow restoration of the blood-brain barrier. Fasted rats ( $n=4$ for each genotype) were anesthetized before food intake, and satiated rats $(n=4$ for each genotype) after food intake.

Recordings started once the electrodes were implanted, and lasted for approximately $3 \mathrm{~h}$. Currents obtained after the signal stabilization corresponded to the initial steady state of the animal, i.e., fasted or satiated. To evaluate possible fluctuations of central glucose level during dynamic glycemia conditions, an i.p. injection of glucose (Lavoisier, Paris, France 30\%; i.p. 3 g/kg) to the fasted rats, or a subcutaneous injection of insulin (Sigma, Saint Quentin-Fallavier, France; $7.5 \mathrm{U} / \mathrm{mL}$; subcutaneous, 25 $\mathrm{U} / \mathrm{kg}$ ) to the satiated rats, were given to measure the effects of acute modifications in peripheral glucose levels on central structures ( $\mathrm{OB}$ and cortex). $1 \mathrm{~h}$ later, rats in the induced hyperglycemic state were injected with insulin and rats in the induced hypoglycemic state were injected with glucose. In 1 of 9 satiated rats glucose was monitored in the OB alone, and three rats received only insulin injection. In 1 of 8 fasted rats, glucose was monitored only in the $\mathrm{OB}$, and three rats received only glucose injection. When recordings ended, rats were euthanized using sodium pentobarbital (i.p. $3 \mathrm{~g} / \mathrm{kg}$ ).

\section{STATISTICAL ANALYSIS}

Data are shown as mean values \pm SEM. For olfactory detection all percentage measures were transformed using the arcsine square root transformation to normalize the data and stabilize variance (Sokal and Rohlf, 1981). For behavioral data, Western Blot data, and extracellular glucose measurements, statistical analysis were performed by either a Student's $t$-test or one- or two-way repeated-measures ANOVA depending on the data set. A Student-Newman-Keuls (SNK) post hoc test was used to complete the analysis when appropriate (Statview software). Physiological parameters (glycemia, plasma and $\mathrm{OB}$ insulin level) were analyzed using a non-parametric MannWhitney test, or Wilcoxon test when data were paired (Statview Software).

\section{RESULTS}

EFFECT OF FOOD RESTRICTION ON BODY WEIGHT OF LEAN AND OBESE ZUCKER RATS

Before any other experiment, $f a /+$ and $f a / f a$ Zucker rats were gradually habituated to a $20 \mathrm{~h} /$ day FR schedule (Figure 1A). In order to determine the effect of FR schedule on weight gain, body weight of the rats was measured, on their arrival, just before the FR beginning and after 3-4 weeks of FR corresponding to the end 
of the experimental procedures (Figure 3). On their arrival, the rats were 7-8 weeks old and the body weight of the two genotypes was already significantly different $(299 \pm 7.2 \mathrm{~g} v s .344 \pm 11.8 \mathrm{~g}$ in $f a /+v s$. fa/fa respectively; $P<0.001$ Mann Whitney test). At the end of the experimental procedures, the difference in the body weight between $f a /+$ and $f a / f a$ and rats was larger $(312 \pm 7.1 \mathrm{~g}$ vs. $412 \pm 7.1 \mathrm{~g}$ in $f a /+v s$. $f a / f a$ respectively; $P<0.0001$ Mann Whitney test). While the $\mathrm{fa} /+$ rats' body weight remained stable during the FR, $(306 \pm 5.7 \mathrm{~g} v s .312 .3 \pm 4.4 \mathrm{~g}$ before FR $v s$. after the experimental procedure, $P=0.1$, paired $t$-test) the $f a / f a$ rats' body weight had continued to increase $(372.9 \pm 7.4 \mathrm{~g} v s .412 \pm$ $7.1 \mathrm{~g}$ before FR $v s$. after the experimental procedure, $P<0.0001$ paired $t$-test).

\section{EFFECT OF FEEDING STATE ON GLYCEMIA, INSULINEMIA, AND OB INSULIN LEVELS IN LEAN AND OBESE ZUCKER RATS}

In order to characterize the physiological hallmarks of the two genotypes of Zucker rats and to evaluate the physiological effects of the feeding state, glycemia, as well as plasma and $\mathrm{OB}$ insulin levels were measured in both $20 \mathrm{~h}$ fasted and satiated $f a /+$ and $f a / f a$ Zucker rats (Table 1). A two-way ANOVA

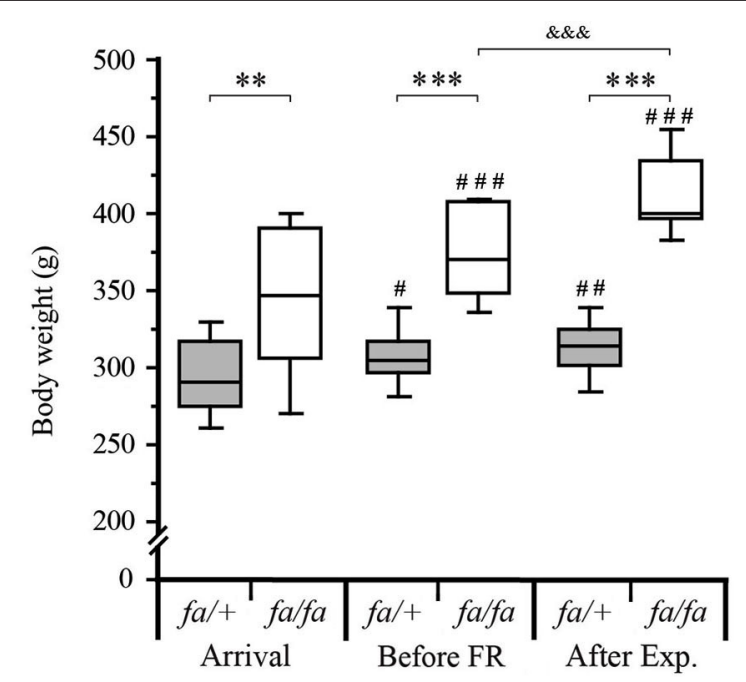

FIGURE 3 | Monitoring of body weight of $\mathrm{fa} /+$ and fa/fa Zucker rats during the experiments. On their arrival, the body weight of the $\mathrm{fa} / \mathrm{+}$ and $\mathrm{fa} / \mathrm{fa}$ Zucker rats (7-8 weeks old), was already significantly different (299 \pm 7.2 g vs. $344 \pm 11.8$ g lean vs. obese respectively; $\left.{ }^{* *} P<0.001\right)$. Between their arrival and before food restriction (FR, 10-11 weeks old) the body weight of the two Zucker rats genotype had increased $(299 \pm 7.2 \mathrm{~g}$ to 306 $\pm 5.7 \mathrm{~g}$ for lean; $\#<0.05$ and $344 \pm 11.8 \mathrm{~g}$ to $372.9 \pm 7.4 \mathrm{~g}$ for obese; \#\#\# $P<0.001)$ and the body weight difference between lean and obese rats was more pronounced $(* * * P<0.0001)$. After the experimental procedure (After Exp) corresponding to 2 weeks of FR, the body weight of $\mathrm{fa} /+$ rats stayed significantly different compared to their body weight measured at their arrival (\#\# $P<0.001$ ) but it was not significantly different compared to those measured before FR (306 $\pm 5.7 \mathrm{~g}$ vs. $312.3 \pm 4.4 \mathrm{~g} ; P=0.1)$. The $\mathrm{fa} / \mathrm{fa}$ rats body weight had continued to increase (372.9 $\pm 7.4 \mathrm{~g}$ before FR vs. $412 \pm 7.1 \mathrm{~g}$ after Exp.; \&\&\& $P<0.0001)$. Values are shown as medians \pm interquartile range, \# compared to the body weight at the arrival of each genotype group the statistical analyses were performed using paired $t$-test, $n=16$ per genotype. with feeding state and genotype as factors revealed a significant effect of these two factors on all three measurements; glycemia $\left(F_{(1,20)}=8.4, P<0.01\right.$ and $F_{(1,20)}=5.0, P<0.05$ respectively), plasma $\left(F_{(1,20)}=14.4, P<0.005\right.$ and $F_{(1,20)}=247.3$, $P<0.0001$ respectively) and $\mathrm{OB}$ insulin levels $\left(F_{(1,20)}=38.7\right.$, $P<0.0001$ and $F_{(1,20)}=320.7, P<0.0001$ respectively). For each genotype, the three measurements were significantly higher in satiated than in fasted rats (Table 1: Mann-Whitney tests).

By comparing the two genotypes, obese $f a / f a$ rats were moderately hyperglycemic (only in satiated state), compared to lean $\mathrm{fa} /+$ rats and their insulin levels (in plasma and in OB) were higher than in $\mathrm{fa} /+$ regardless of the feeding state (Table 1: MannWhitney tests). The difference in insulin concentration between the two rat strains was smaller in the $\mathrm{OB}$ (3-3.87 fold more concentrated in satiated and fasted states, respectively) than in the plasma (5.5-10 fold more concentrated in satiated and fasted states, respectively).

\section{EFFECT OF FEEDING STATE AND OF GENOTYPE ON OLFACTORY DETECTION}

In order to compare the olfactory detection abilities of $f a /+$ and $f a / f a$ rats in fasted and satiated states, a behavioral test based on COA was performed and olfactory detection indexes were measured for ISO dilutions ranging from $10^{-11}$ to $10^{-7}$ (Figures 4A,B). During the olfactory detection test (Figure 1B, from day 4 to day 8, D4 to D8), a two-way ANOVA with feeding state and odor as factors revealed significant effects of feeding state $\left(f a /+F_{(1,88)}=15.8, P<0.01 ; f a / f a F_{(1,88)}=30.4, P<0.0001\right)$ and odor $\left(f a /+F_{(4,88)}=27.1, P<0.0001 ; f a / f a F_{(4,88)}=15.8\right.$, $P<0.0001)$ on olfactory detection indexes. Post hoc analyses (paired $t$-test) revealed that $f a /+$ rats have higher olfactory detection indexes in the fasted state compared to the satiated state, for ISO $10^{-8}$ (fasted: $62.6 \pm 6.8 \%$, satiated: $19.5 \pm 3.9 \%$, $P<0.0001$ ) and ISO $10^{-7}$ (fasted: $95.3 \pm 1.7 \%$, satiated: $55.6 \pm$ $9.0 \%, P<0.0005)$. This effect was even more pronounced in $\mathrm{fa} / \mathrm{fa}$ rats, which have higher olfactory detection indexes in the fasted state compared to the satiated state for a concentration as low as ISO $10^{-9}$ (fasted: $51.3 \pm 9.0 \%$; satiated: $17.0 \pm 4.0 \%, P<0.01$ ) but also for ISO $10^{-8}$ (fasted: $58.2 \pm 7.4 \%$, satiated: $12.9 \pm 3.2 \%$, $P<0.0001$ ) and ISO $10^{-7}$ (fasted: $89.8 \pm 5.6 \%$, satiated: $61.2 \pm$ $9.2 \%, P<0.005)$.

To ensure that the COA was robust and maintained throughout the olfactory detection test, the olfactory detection indexes were measured at ISO $10^{-5}$ for all the animals, before (Figure 1B, Aversion test, on D3) and after (Aversion re-test, on D9) the olfactory detection test. During the aversion test (D3), carried out after the conditioning, the animals licked almost exclusively from the pure-water tube, as demonstrated by olfactory indexes close to $100 \%$ (Figure 4C, fasted $\mathrm{fa} /+\mathrm{t} 99.97 \pm 0.03 \%$, satiated $f a /+: 99.98 \pm 0.02 \%$, fasted $f a / f a: 99.85 \pm 0.15 \%$, satiated $f a / f a$ : $99.80 \pm 0.10 \%)$ showing that the COA was well established at the beginning of the olfactory detection test. On the last day of the behavioral experiment (Aversion re-test, D9), all the animals drank, again, almost exclusively at the pure-water tube (fasted $\mathrm{fa} / \mathrm{+}: 99.90 \pm 0.06 \%$, satiated $\mathrm{fa} / \mathrm{+}: 99.38 \pm 0.23 \%$, fasted $\mathrm{fa} / \mathrm{fa}$ : $98.01 \pm 1.80 \%$, satiated $\mathrm{fa} / \mathrm{fa}$ : $98.05 \pm 0.90 \%)$, 
Table 1 | The effects of feeding state on glycemia, plasmatic and OB insulin levels in lean fa/+ and obese fa/fa Zucker rats.

\begin{tabular}{|c|c|c|c|c|c|c|}
\hline & \multirow[t]{2}{*}{$\begin{array}{c}\text { Zucker } \\
\text { genotype }\end{array}$} & \multirow[t]{2}{*}{$\begin{array}{l}\text { Fast. } \\
n=6\end{array}$} & \multirow[t]{2}{*}{$\begin{array}{l}\text { Sat. } \\
n=6\end{array}$} & \multirow[t]{2}{*}{$\begin{array}{c}\text { Mann-Whitney } \\
\text { Sat. vs. Fast. }\end{array}$} & \multicolumn{2}{|c|}{$\begin{array}{c}\text { Mann-Whitney } \\
\text { fa/+ vs. fa/fa }\end{array}$} \\
\hline & & & & & Fast. & Sat. \\
\hline \multirow[t]{2}{*}{ Glycemia (mM) } & $\mathrm{fa} /+$ & $6.15 \pm 0.2$ & $7.0 \pm 0.4$ & $P<0.05$ & ns & $P<0.05$ \\
\hline & $\mathrm{fa} / \mathrm{fa}$ & $6.51 \pm 0.3$ & $10.67 \pm 1.7$ & $P<0.005$ & & \\
\hline \multirow[t]{2}{*}{ Plasmatic insulin $(\mu \mathrm{g} / \mathrm{L})$} & $\mathrm{fa} /+$ & $1.04 \pm 0.04$ & $2.52 \pm 0.02$ & $P<0.005$ & $P<0.005$ & $P<0.005$ \\
\hline & $f a / f a$ & $10.39 \pm 0.5$ & $13.90 \pm 0.2$ & $P<0.05$ & & \\
\hline \multirow[t]{2}{*}{ OB insulin (ng/g) } & $\mathrm{fa} /+$ & $0.16 \pm 0.01$ & $0.28 \pm 0.1$ & $P<0.005$ & $P<0.005$ & $P<0.005$ \\
\hline & $f a / f a$ & $0.62 \pm 0.01$ & $0.86 \pm 0.02$ & $P<0.005$ & & \\
\hline
\end{tabular}

For each genotype, glycemia, OB and plasma insulin levels were statistically higher in satiated compared to fasted animals. For each feeding state (fasted; Fast. and satiated; Sat.) levels of these three types of measure were significantly higher in fa/fa rats compared to their fa/+ counterparts, except for glycemia of fasted rats (Mann-Whitney test, $n=6 /$ feeding state/genotype Zucker, $n s: P>0.05$ ).

indicating that COA was maintained throughout the behavioral experiment.

In order to further compare the olfactory detection abilities of $\mathrm{fa} /+$ and $\mathrm{fa} / \mathrm{fa}$ rats, the number of licks were measured during the first consumption of each given ISO concentration in the experimental device (Figures 4D-F). This measurement shows the number of licks that were necessary for the animal to detect the aversive ISO odor diluted in the drinking solution. One should expect that the better the animal can detect the ISO, the lower the number of licks during the first consumption would be. A three-way ANOVA with genotype, feeding state and odor as factors revealed significant effects of these three factors on the number of licks during the first ISO consumption (genotype: $F_{(1,132)}=4.3, P<0.05$, feeding state: $F_{(1,132)}=15.5, P<0.0005$, odor: $\left.F_{(4,132)}=7.1, P<0.0001\right)$. Fasted animals required fewer licks than satiated animals to detect and leave the aversive solution (post hoc analysis SNK), further demonstrating that animals have better olfactory sensitivity when fasted than satiated. In fasted states (Figure 4D), $f a / f a$ rats required fewer licks than $f a /+$ rats to detect and leave the aversive solution at ISO $10^{-11}(\mathrm{fa} / \mathrm{fa}: 33.89$ $\pm 7.6, \mathrm{fa} /+\mathrm{:} 220.3 \pm 78.0, P<0.05 t$-test $)$, and at ISO $10^{-8}(\mathrm{fa} / \mathrm{fa}$ $15.67 .5 \pm 7.3, f a /+: 80.17 \pm 29.2, P<0.05 t$-test $)$. In satiated state (Figure 4E) $\mathrm{fa} / \mathrm{fa}$ leaved the aversive solution faster than $f a /+$ rats at ISO $10^{-10}(f a / f a: ~ 138.25 \pm 21.2, f a /+: 247.67 \pm 44.3$, $P<0.05 t$-test) and also at ISO $10^{-9}$ ( $\mathrm{fa} / \mathrm{fa}: 142.41 \pm 35.2, \mathrm{fa} /+$ : $275.33 \pm 40.0, P<0.05 t$-test). In addition when data obtained in fasted and in satiated states were pooled (Figure 4F), the lick number during the first burst was significantly lower for $\mathrm{fa} / \mathrm{fa}$ rats compared to their lean counterparts at ISO $10^{-11}$, ISO $10^{-8}$ and ISO $10^{-9}$ ( $P<0.001, P<0.05, P<0.05$ respectively, $t$-test $)$. Neither genotype $(f a /+v s$. $f a / f a$ for each feeding state: $t$-test $)$ nor feeding state (fasted vs. satiated for each genotype: paired $t$-test) effect was observed on the lick number of the first burst at the pure water tube during the habituation period observed $(P>0.05$, fasted rats: $f a /+76.16 \pm 21.5, f a / f a 55.16 \pm 6.11$; satiated rats: $f a /+110.8 \pm 17.1, f a / f a 78.25 \pm 11.1)$. Altogether, these results indicated that $f a / f a$ rats have a better olfactory sensitivity than $\mathrm{fa} /+$ rats.

\section{EFFECTS OF FEEDING STATE ON EXPRESSION OF GLUT4 AND SGLT1 IN OB OF THE TWO GENOTYPES}

In order to analyze the localization of SGLT1 and GLUT4 within the different $\mathrm{OB}$ layers in Zucker $f a / f a$ and $f a /+$ rats, an immunofluorescence experiment was performed. SGLT1 and GLUT4 were found in different layers of the OB. In both lean and obese Zucker rats, immunostaining of SGLT1, a transporter of non-metabolized glucose, revealed a layer-specific pattern (Figures 5A,B). The highest staining was observed in the inner part of EPL (iEPL) with a stronger expression in $\mathrm{fa} / \mathrm{fa}$ rats (Figure 5A). In the two genotypes, the outer part of the EPL (oEPL) was unlabeled (Figures 5A,B). SGLT1 immunostaining was also detected in some glomeruli more particularly in $f a / f a$ Zucker rats. In both lean and obese Zucker rats, the highest level of GLUT4 immunostaining was detected in the glomerular layer (GL) and in the mitral cell layer (MCL; Figures 5C,D) while the nerve layer appeared unstained. Within the glomerular neuropil, GLUT4 staining varied from strongly to unlabeled glomeruli. The pictures shown in the manuscript are representative of SGLT1 and GLUT4 immunostaining in the OB of both rat genotypes and were consistent across rats within each group. We could not see any difference in the localization of GLUT4 and SGLT1 in fasted rats compared to satiated rats, for both genotypes (data not shown).

The effects of feeding state and genotype on GLUT4 and SGLT1 protein levels in the OB were analyzed by Western blotting (Figure 6). Total tissue GLUT4 and SGLT1 were analyzed using the total protein recovery from the OBs of four satiated and four fasted rats of each genotype (Figure 6A). A two-way ANOVA on SGLT1 protein levels (Figure 6B), with feeding state and genotype as factors, revealed no effect of feeding state, but a significant effect of genotype $\left(F_{(1,12)}=14.87, P<0.005\right)$. Post hoc analyses (SNK) of these data confirmed a higher expression of SGLT1 in $f a / f a$ Zucker rats compared to $f a /+$ rats. This higher expression is observed in the satiated state only, as revealed by Mann-Whitney test $(P<0.05)$. Neither feeding state nor genotype had an effect on GLUT4 levels (Figure 6C) $\left(F_{(1,12)}=0.54\right.$, $P=0.47$ and $F_{(1,12)}=1.146, P=0.3$, respectively). Together these results indicated that SGLT1 protein levels were significantly increased in the $\mathrm{OB}$ of Zucker $f a / f a$ rats compared to $f a /+$ rats.

\section{REAL TIME IN VIVO MONITORING OF EXTRACELLULAR FLUID GLUCOSE IN OB AND CORTEX OF LEAN AND OBESE ZUCKER RATS During steady states}

Extracellular fluid glucose concentration ([Gluc $]_{\mathrm{ECF}}$ ) was measured simultaneously in the $\mathrm{OB}$ glomerular layer and the 


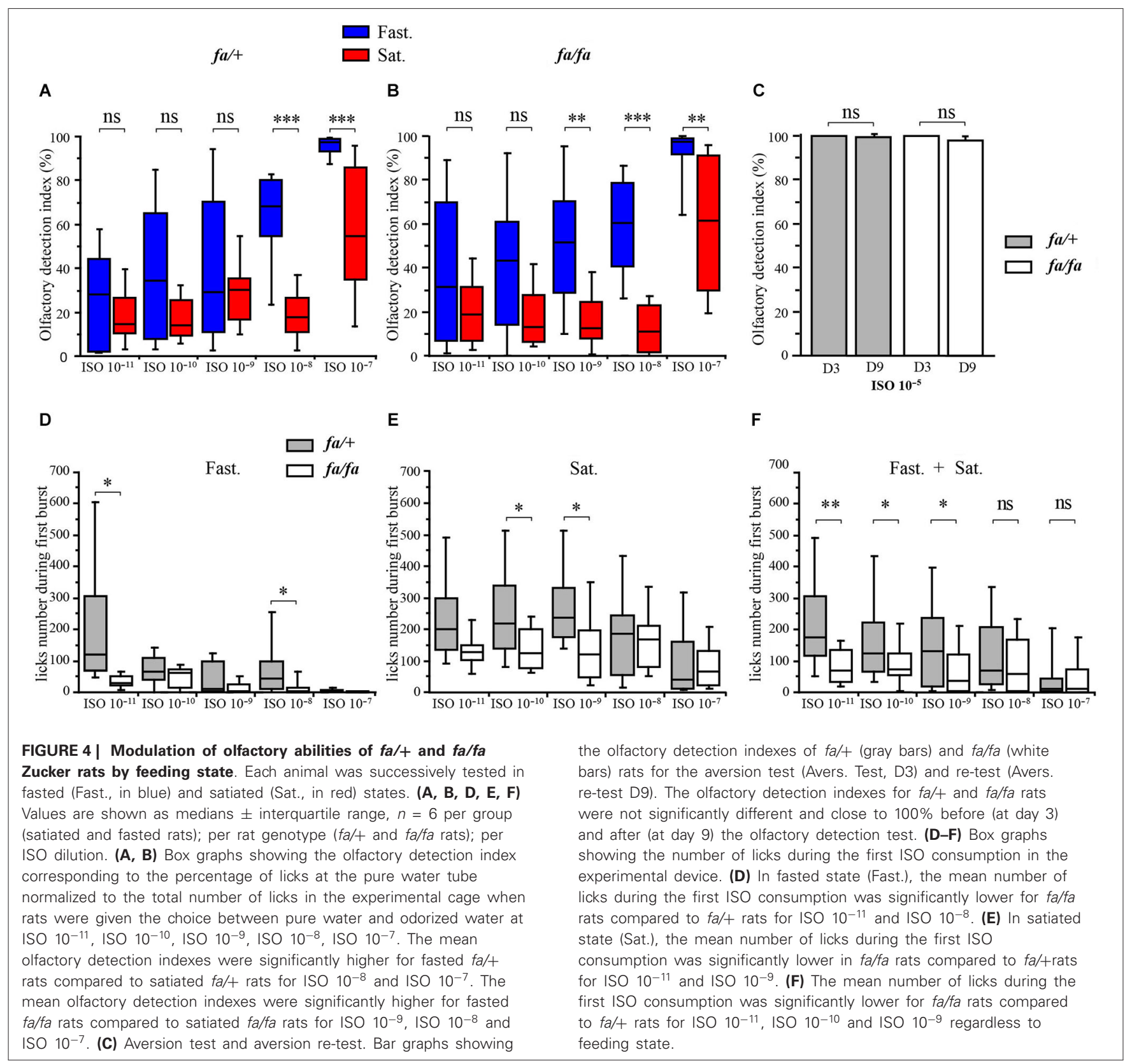

somatosensory cortex of lean or obese Zucker rats, in fasted or satiated state. 2 weeks prior to the experimental study, animals were habituated to a $2 \mathrm{~h}$ feeding/ $22 \mathrm{~h}$ starvation schedule. At the beginning of the experiment, the metabolic status of the rats was considered to be steady, since satiety or hunger had been maintained for several hours. Glycemia was monitored to check each metabolic (fasted or satiated) steady state. As shown in Table 1, glycemia was significantly higher in satiated than in fasted state and in $f a / f a$ than in $f a /+$ rats. The effects of feeding state and genotype on [Gluc $]_{\mathrm{ECF}}$ in $\mathrm{OB}$ and cortex were analyzed by using a three-way ANOVA with brain areas (OB and cortex), feeding state and genotype as factors. A significant effect on [Gluc $]_{\text {ECF }}$ was observed during the initial steady state for factors "brain areas" and "genotype" $\left(F_{(1,24)}=13.6, P<0.005\right.$; $F_{(1,24)}=21.6, P<0.0001$ respectively, Figure 7). [Gluc] $]_{\mathrm{ECF}}$ was significantly higher in the $\mathrm{OB}$ than in the cortex, and in $f a / f a$ than $f a /+$ rats (SNK post hoc tests). No significant effect of feeding state was observed on [Gluc] ECF despite differences in plasma glucose levels between satiated and fasted rats (Table 1). For each genotype, [Gluc] $]_{\mathrm{ECF}}$ was significantly higher in $\mathrm{OB}$ compared to cortex (Wilcoxon test, ${ }^{\star} P<0.05$ for each rat genotype; in mM: Fasted: $f a /+$ in the $\mathrm{OB}, 1.48 \pm$ 0.35 , in the cortex, $0.92 \pm 0.33 ; \mathrm{fa} / \mathrm{fa} \mathrm{OB}, 3.05 \pm 0.5$, cortex, $1.67 \pm 0.23$; Satiated: $\mathrm{fa} / \mathrm{OB}, 1.48 \pm 0.25$; cortex, $0.55 \pm$ 0.09 ; $\mathrm{fa} / \mathrm{fa} \mathrm{OB}, 2.35 \pm 0.5$; cortex $1.5 \pm 0.15$, Figure 7 ). In both $\mathrm{OB}$ and cortex [Gluc] ECF were higher in $\mathrm{fa} / \mathrm{fa}$ compared 

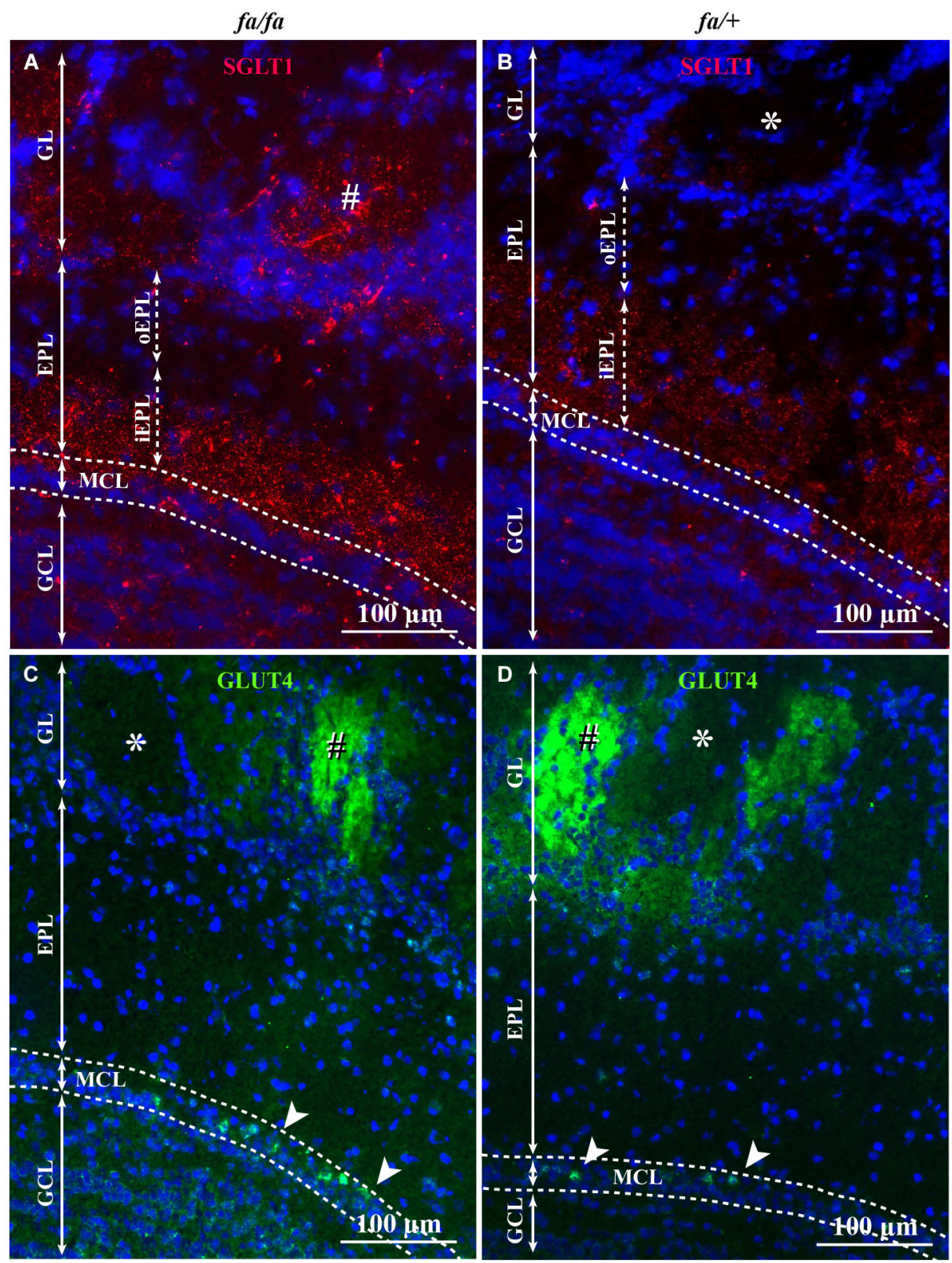

FIGURE 5 | SGLT1 and GLUT4 localization in OB layers of $\mathrm{fa} /+$ and fa/fa Zucker rats. Representative SGLT1 $(\mathbf{A}, \mathbf{B})$ and GLUT4 $(\mathbf{C}, \mathbf{D})$ immunolocalization among OB layers of $\mathrm{fa} / \mathrm{fa}(\mathbf{A}, \mathbf{C})$ and $\mathrm{fa} / \mathrm{+}(\mathbf{B}, \mathbf{D})$ Zucker rats merged with the nuclear marker DAPI. In fa/fa (A) and fa/t (B) Zucker rats, SGLT1 was mainly found in the inner part of the EPL (iEPL) and the overall expression of SGLT1 is stronger in Zucker fa/fa rats. The outer part (oEPL) was unlabeled. In the GL, some (\#) but not all glomeruli express SGLT1. The number of SGLT1-positive glomeruli is higher in Zucker fa/fa rats compared to Zucker fa/t rats. Very slight SGLT1 immunostaining was also found in the GCL. In fa/fa (C) and $\mathrm{fa} /+$ (D) Zucker rats, no difference of immunolocalization of GLUT4 was observed. GLUT4 was located in the glomerular layer. Glomeruli showed different level of GLUT4 expression (strongly labeled: \#, not labeled: *). Some mitral cells (arrowhead) were intensely

immunostained (EPL: external plexiform layer, GCL: granular cell layer, GL: glomerular layer, MCL: mitral cell layer). to $\mathrm{fa} /+$ (Mann Whitney test, $€ P<0.05$ for each area brain, Figure 7).

\section{During dynamic states following insulin and glucose injections}

Real time in vivo measurements of [Gluc $]_{\mathrm{ECF}}$ were recorded simultaneously from the $\mathrm{OB}$ and the somatosensory cortex of $f a /+$ and $f a / f a$ Zucker rats either fasted (Figures 8A,C respectively) or satiated (Figures 8B,D respectively). For each genotype, the two groups of rats (fasted and satiated) received two injections: one of glucose (G-Inj) and one of insulin (I-Ins). Fasted rats (Figures $\mathbf{8 A}, \mathrm{C}$ ) first received a glucose injection (G-Inj1) followed by an insulin injection (I-Inj2). This order 
A

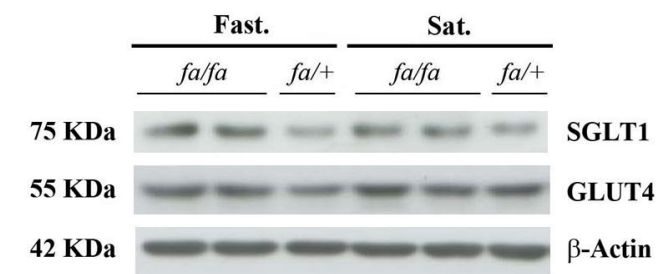

B

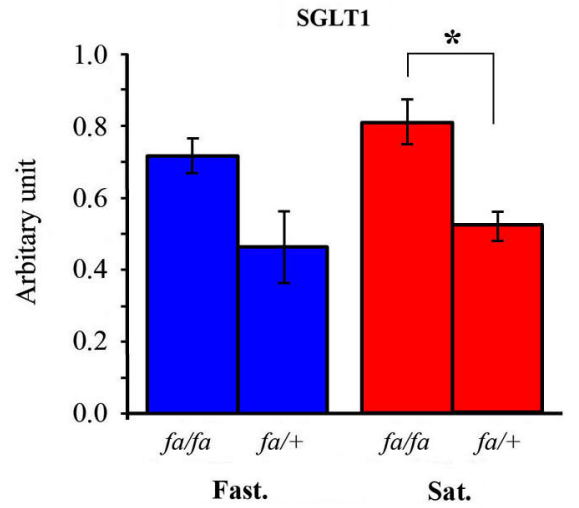

C

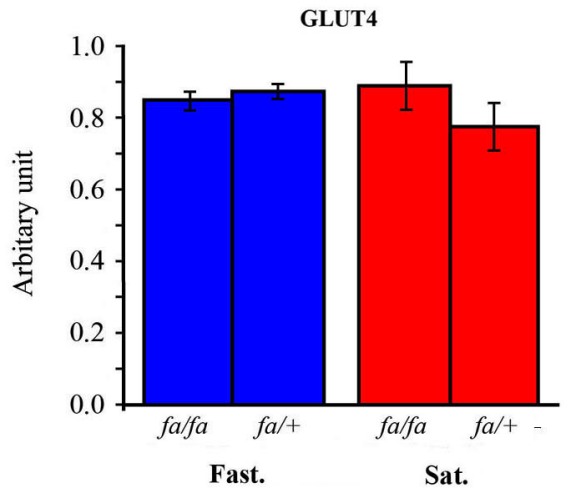

FIGURE 6 | Western blot analysis of SGLT1 and GLUT4 in OB homogenates from fasted (Fast.) or satiated (Sat.) fa/fa and fa/+ Zucker rats. (A) A representative blot. The intensity of each band was measured by densitometry and normalized to the housekeeping protein actin, as a loading control. (B) SGLT1 levels were significantly greater in satiated fa/fa rats compared to satiated fa/+ rats. (C) GLUT4 levels were not significantly different significantly regardless of the rat genotype and the feeding state. ${ }^{*} P<0.05$, mean \pm S.E.M., $n=4 /$ feeding state/genotype.

was reversed for satiated rats (Figures 8B,D, I-Inj1, G-Inj2). Glucose and insulin injections induced substantial fluctuations in extracellular glucose levels, especially in the $\mathrm{OB}$ of $\mathrm{fa} /+$ rats. In $f a / f a$ compared to $f a /+$ rats, glucose injection (G-Inj) induced less pronounced variations of [Gluc $]_{\text {ECF. }}$ and insulin injection (I-Inj) induced a slower decrease of [Gluc] ECF. For each feeding state (satiated and fasted) a mixed ANOVA was performed with an intra-subject factor, corresponding to the three conditions (steady-state, Inj1 and Inj2) and two intersubject factors: genotype (lean and obese) and brain area (OB and Cortex). Both in fasted (Figure 8E) and satiated

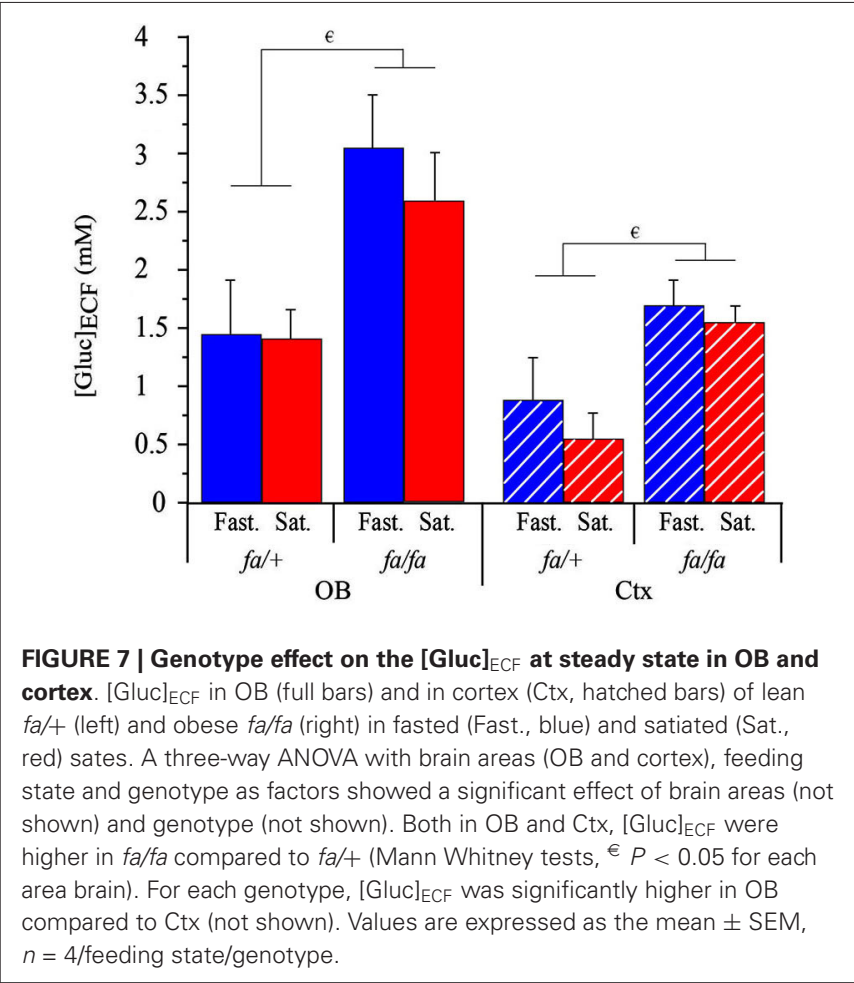

(Figure 8F) rats, the statistical analysis showed a significant difference between conditions $\left(F_{(2,24)}=26.66, P<0.0001\right.$; $F_{(2,24)}=29.28, P<0.0001$, respectively), genotype $\left(F_{(1,24)}=8.35\right.$, ${ }^{\#} P<0.01$ Figure 8E; $F_{(1,24)}=22.48$, \#\# $P<0.0005$, respectively Figure 8F) and brain areas $\left(F_{(1,24)}=11.91, P<0.005\right.$; $F_{(1,24)}=5.56, P<0.05$, respectively). In each feeding state (satiated and fasted), [Gluc] $]_{\mathrm{ECF}}$ was higher in $f a / f a$ than in $\mathrm{fa} /+$ rats, and in the $\mathrm{OB}$ than in the cortex (SNK post hoc tests). Moreover G-Inj increased [Gluc] ECF significantly above steady-state and I-Inj. levels, and I-Inj decreased [Gluc] ECF significantly below steady-state and G-Inj levels (SNK post hoc tests).

Next, we calculated the difference of [Gluc $]_{\text {ECF }}$ measurements between steady state and after the first injection (G-Inj1 or I-Inj1). This measurement corresponds to the fluctuations of [Gluc] $]_{\mathrm{ECF}}$ shown in Figure 9. In each group (satiated and fasted rats) a two way ANOVA was performed with brain areas (OB and cortex) and genotype $(f a /+$ and $f a / f a)$ as factors. The ANOVA demonstrated a significant effect of brain areas in fasted $\left(F_{(1,12)}=7.03, P<0.01\right)$ and satiated $\left(F_{(1,12)}=9.81, P<0.01\right)$ rats. Greatest [Gluc $]_{\mathrm{ECF}}$ fluctuations were observed in the $\mathrm{OB}$ compared to the cortex (SNK post hoc tests). The ANOVA also demonstrated a significant difference on [Gluc] $]_{\text {ECF }}$ fluctuation between $f a /+$ and $f a / f a$ rats, but only in fasted rats (Figure 9, $F_{(1,12)}=5.1,{ }^{\#} P<0.05$ ), the fluctuations being greatest in $f a /+$ than in $f a / f a$ rats. Further analysis demonstrated that this was due to fluctuations in the OB, because glucose injections had induced smallest fluctuations of [Gluc $]_{\mathrm{ECF}}$ in the OB of $f a / f a$ rats than of $f a /+$ (Mann Whitney test $\left.{ }^{\phi} P<0.05\right)$. In satiated $f a /+$ rats only, insulin injection, had 


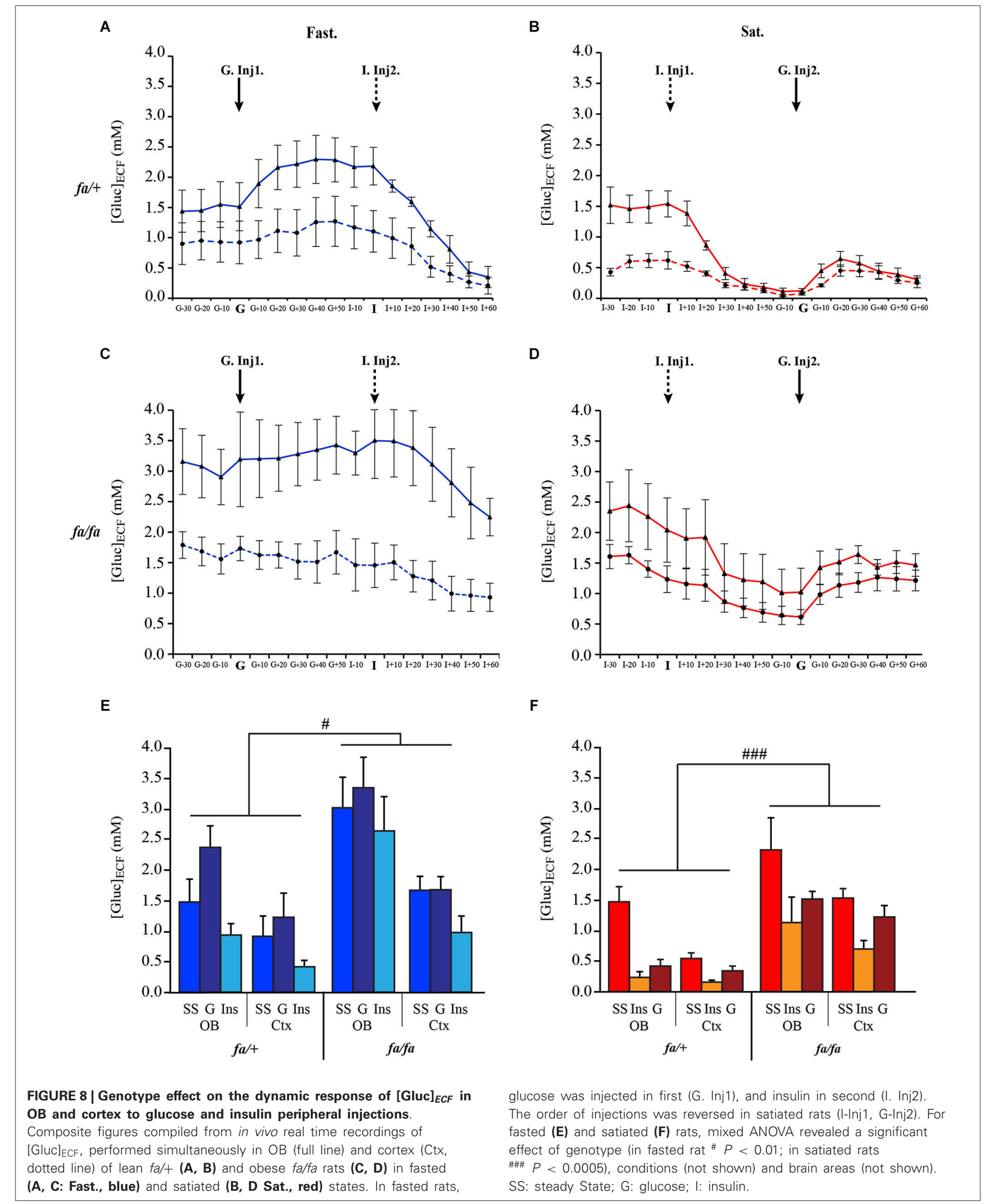




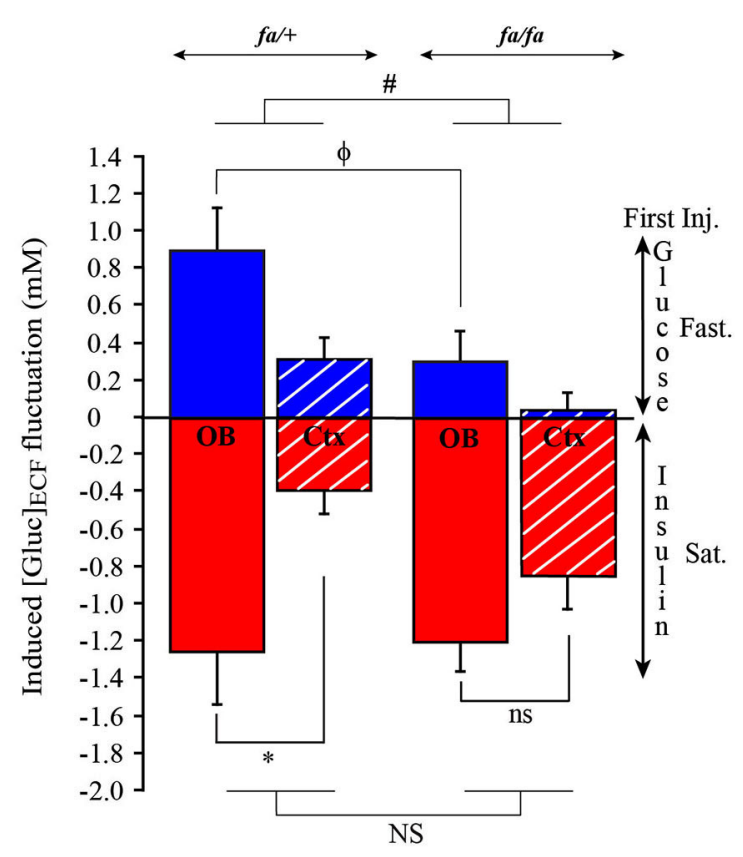

FIGURE 9 | Genotype effect on [Gluc] $]_{E C F}$ fluctuations induced by the first injection of either Glucose or Insulin in OB and cortex. Bars represent the difference calculated between [Gluc] ECF measured at steady state and after the first injection of glucose (blue) or insulin (red). [Gluc] $]_{E C F}$ fluctuations were observed in OB (full bar) and cortex (Ctx, dotted bar) of lean $\mathrm{fa} /+$ (left) and obese fa/fa rats (right). When glucose was injected in first in fasted rats (Fast.), a significant effect of the genotype on [Gluc] $]_{E C F}$ fluctuation was observed (ANOVA test, $\# P<0.05$; NS $P>0.05$ ), [Gluc] ${ }_{E C F}$ fluctuation being smaller in the OB of fa/fa compared to fa/ + rats (Mann Whitney, $\left.{ }^{\phi} P<0.05\right)$. No difference was observed in the Ctx. When insulin was injected in first in satiated rats (Sat.), only in fa/+ rats [Gluc $]_{E C F}$ fluctuation was significantly higher in OB than in cortex (Mann Whitney, ${ }^{*} P<0.05$; ns $P>0.05$.

induced a greater $[\mathrm{Gluc}]_{\mathrm{ECF}}$ fluctuation in the $\mathrm{OB}$ than in the cortex (Figure 9, Mann Whitney tests ${ }^{*} P<0.05$ ).

\section{DISCUSSION}

The present study provides new information on the impact of a metabolic disorder on olfactory abilities and glucosesensing in the olfactory system. Indeed, obese fa/fa Zucker rats, displayed a higher olfactory sensitivity than lean $\mathrm{fa} /+$ rats, regardless of their feeding status (fasted or satiated). In addition, the expression of glucose-sensing markers and glucose fluctuations in the $\mathrm{OB}$ were strikingly different between the two rat genotypes. First, SGLT1 expression was higher in the $\mathrm{OB}$ of obese rats compared with lean rats; while GLUT4 levels were similar for the two rat genotypes. Second, [Gluc $]_{\mathrm{ECF}}$ measured at steady states (fasted or satiated) was higher in $f a / f a$ rats than in $f a /+$ rats, with a consistently higher concentration measured in the $\mathrm{OB}$ compared to the cortex. Third, OB [Gluc $]_{\mathrm{ECF}}$ was differentially affected in $f a / f a$ and $f a /+$ rats when glycemia was dynamically modified by peripheral injections of glucose or insulin. Indeed, after glucose injection (acute hyperglycemia), obese rats showed a slight increase of $\mathrm{OB}[\mathrm{Gluc}]_{\mathrm{ECF}}(\approx 0.2 \mathrm{mM})$, whereas lean rats demonstrated a much higher increase $(0.9 \mathrm{mM})$. Insulin injection (acute hypoglycemia) decreased [Gluc $]_{\mathrm{ECF}}$ similarly in the $\mathrm{OB}$ of the two rat strains. Differences observed in olfactory detection between obese and lean rats will be discussed in link with the modulation of glucose-sensing and of food intake.

\section{OBESE $f a / f a$ ZUCKER RATS HAVE HIGHER OB INSULIN

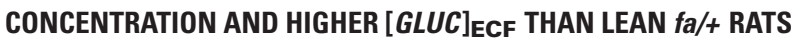

In addition to peripheral hyperinsulinemia and hyperglycemia, obese Zucker $f a / f a$ rats displayed higher OB insulin levels than their lean counterparts. This is consistent with previous studies that reported that insulin level is highly increased in the cerebrospinal fluid of $f a / f a$ compared to $f a /+$ Zucker rats (Stein et al., 1983; Figlewicz et al., 1985). These results provide evidence that brain insulin is derived from circulating insulin and suggest that obese Zucker rats do not have any defect of insulin transport through the blood brain barrier (BBB). Although some early contradictory studies suggested that insulin binding was altered in the brain of obese fa/fa Zucker rats (Melnyk, 1987; Wilcox et al., 1989), subsequent reports convincingly demonstrated that insulin receptors (IRs) had similar expression, number, distribution, binding affinity and tyrosine kinase activity in the brain of lean and obese Zucker rats (Livingston et al., 1993; Amessou et al., 2010). Interestingly, rats carrying at least one copy of the $f a$ allele $(f a / f a$ and $f a /+)$ present lower insulin concentration (Baskin et al., 1985) and lower insulin binding (Figlewicz et al., 1985) than nonmutated $+/+$ rats. Therefore, these deficits are independent of a severe obese phenotype because they are found in obese $f a / f a$ and lean $\mathrm{fa} / \mathrm{+}$ rats. Altogether, these data indicate that changes in insulin signaling are unlikely to account for the differences observed in the present study.

In both $\mathrm{OB}$ and cortex, [Gluc $]_{\mathrm{ECF}}$ was found to be higher in $f a / f a$ than in $f a /+$ Zucker rats. This is consistent with the higher brain glucose uptake observed in obese rats compared to lean controls (Liistro et al., 2010). It is interesting to note that a higher central glucose availability is associated with a lower local cerebral glucose utilization (Doyle et al., 1993), especially in brain areas implicated in the neuroendocrine regulation of food intake and in odor-taste perception, such as the hypothalamus and the OB (Marfaing-Jallat et al., 1992). Moreover, in both rat genotypes, [Gluc] $]_{\mathrm{ECF}}$ at steady states was found to be higher in the $\mathrm{OB}$ than in the cortex and this is consistent with the compartmentalization of [Gluc $]_{\mathrm{ECF}}$ according to the brain area studied and to the level of neural activity (McNay and Gold, 1999; McNay et al., 2001). Work from the group of Magistretti has demonstrated that neuronal activity and glucose metabolism are tied together (Magistretti et al., 1999). Indeed, OB presents a higher functional activity than the somatosensory cortex (Yang et al., 1998). Moreover, the OB glomerular layer not only has remarkably high glucose consumption rates (Nawroth et al., 2007) but also possesses very high capillary network density (Chaigneau et al., 2007) combined with a distinct microvasculature (Yang et al., 1998) and a high permeability of the BBB (Ueno et al., 1996). Together these hallmarks suggest that OB not only elicits high-energy demands but could also be a glucose-sensing brain area. 


\section{OBESE $f a / f a$ ZUCKER RATS HAVE A HIGHER EXPRESSION OF GLUCOSE-SENSING MOLECULAR MARKERS IN THE OB THAN LEAN fa/+ RATS}

In the $\mathrm{OB}$ of both rat genotypes, the molecular markers of glucose-sensing GLUT4 and SGLT1 were detected in different layers of the OB. GLUT4 immunostaining was observed in glomeruli and in some mitral cells, while SGLT1 was mainly observed in the iEPL. This distribution is similar to that shown by in situ hybridization in Allen Brain Atlas (Allen Institute for Brain Science, 2010). This distinct regional location of GLUT4 and SGLT1 support the idea that these two families of glucose transporters play different roles in neuronal network processing as it has been previously reported in other brain areas (Yu et al., 2010, 2013).

Obesity did not modulate GLUT4 expression in the OB, since obese $f a / f a$ and lean $f a /+$ rats presented similar GLUT4 localization and level of expression. However, obesity changed SGLT1 expression, which was higher in satiated $f a / f a$ than in satiated $\mathrm{fa} /+$. Concerning GLUT4, our results are in agreement with previous work performed on hyperinsulinemic-hyperglycemic $\mathrm{db} / \mathrm{db}$ mice, which showed that GLUT4 protein levels were unchanged in the cortex and the OB (Vannucci et al., 1998). Accordingly, GLUT4 mRNA levels did not change in the cortex of hyperinsulinemic fa/fa Zucker rats (Alquier et al., 2006). Winocur and collaborators suggested that the stability of GLUT4 expression is related to the insulin resistance of $f a / f a$ Zucker rats (Winocur et al., 2005), because GLUT4 translocation to the plasma membrane can no longer be triggered by insulin signaling as it is in a normal metabolic context (McEwen and Reagan, 2004). Indeed, in the hippocampus of Zucker rats, GLUT4 association to the plasma membrane was significantly reduced although total GLUT4 protein expression was not affected (Winocur et al., 2005). In order to confirm this hypothesis, it will be interesting to further study and compare GLUT4 subcellular localization in the OB of the two genotypes of Zucker rats. Concerning SGLT1, the up-regulation observed in the $\mathrm{OB}$ of $f a / f a$ rats is consistent with previous studies performed on peripheral tissues in obese, hyperinsulinemic and diabetic rodent models as well in human (Morton and Hanson, 1984; Ferraris and Vinnakota, 1995; Dyer et al., 2002; Osswald et al., 2005; Tabatabai et al., 2009). In central nervous system, during pathological conditions such as ischemia or epileptic seizure which induce an over-consumption of glucose (Poppe et al., 1997; Elfeber et al., 2004) SGLT1 was up-regulated (Yu et al., 2010, 2013). Up-regulation of SGLT1 is proposed to compensate for impairment in GLUTs function (Yu et al., 2013). Thus, in the context of insulin resistance, the deficiency in GLUT4 translocation could explain the SGLT1 up-regulation.

\section{FASTED RATS HAVE A BETTER OLFACTORY SENSITIVITY THAN SATIATED RATS, REGARDLESS OF THE GENOTYPE}

Olfactory sensitivity of both $f a /+$ and $f a / f a$ Zucker rats is modulated by the feeding states. They have lower olfactory detection and detect the aversive odorant more quickly in the fasted state than in the satiated state, as we previously observed with normalweight Wistar rats (Aimé et al., 2007). Olfactory sensitivity is modulated by a number of peripheral and central signals involved in the regulation of energy balance such as leptin, orexin A, ghrelin and insulin (Julliard et al., 2007; Tong et al., 2011; Aimé et al., 2012; Palouzier-Paulignan et al., 2012). The OB is the target of orexinergic fibers originating from the lateral hypothalamic nucleus (Peyron et al., 1998). In addition, the olfactory system expresses, among others, receptors for orexin A, ghrelin, leptin, insulin, NPY and CCK (for review, see Palouzier-Paulignan et al., 2012). Our results suggest that although many of these signals are altered in the obese Zucker $f a / f a$ rats, the redundancy of orexigenic and anorectic molecules acting on the olfactory system can ultimately maintain the modulation of olfactory sensitivity by the feeding state. For instance, we found that the OB insulin content in both $f a / f a$ and $f a /+$ Zucker was modulated by the feeding states, with satiated animals showing a higher $\mathrm{OB}$ insulin level than fasted animals. Interestingly, we have previously demonstrated in Wistar rats that such fluctuations of $\mathrm{OB}$ insulin levels are sufficient to decrease the olfactory sensitivity of fasted animals to the level of satiated ones (Aimé et al., 2012). Changes of insulin levels in $\mathrm{OB}$ and in plasma were correlated confirming that the $\mathrm{OB}$ is highly sensitive to fluctuations in circulating insulin levels. This result is consistent with the general agreement that $\mathrm{OB}$ is the brain region containing the highest level of IRs (Hill et al., 1986; Unger et al., 1989; Marks et al., 1990). This receptor allows pancreatic insulin to enter the brain across brain capillaries (Schwartz et al., 1990; Banks et al., 1997; Woods et al., 2003; Banks, 2004). At the entire brain level, the rate of insulin entrance is regulated by several physiological factors, including the feeding state (Woods et al., 2003; Banks, 2004). When animals are fasted, the ability of insulin to cross the $\mathrm{BBB}$ is reduced, leading to a positive correlation between blood and cerebrospinal fluid insulin levels (Strubbe et al., 1988). Although one report suggested that OB insulin binding is modulated by the feeding state and reduced by chronic fasting (Marks and Eastman, 1989), we have recently shown that the OB IR expression is not modulated by the feeding state (Aimé et al., 2012). Consistent with the latter, nutrient availability does not modulate IR levels in brain regions involved in energy homeostasis regulation (Bowlby et al., 1997). Together, these data indicate that insulin signaling in the $\mathrm{OB}$ is dependent on the fluctuations of peripheral insulin levels, and participate in the modulation of synaptic transmission of odor-related stimuli by the feeding states.

Interestingly, both genotypes showed similar OB [Gluc $]_{\mathrm{ECF}}$ in steady fasted or satiated states although glycemia was much higher in the satiated state. This is consistent with our previous observation in Wistar rats (data not shown) and could be due to adjustments of the glucose transport capacity at the BBB in response to brain metabolic rate and glucose availability (for review see Bradbury, 1993; Leybaert, 2005; Banks, 2006). Three mechanisms have been proposed to explain the modulation of glucose transport across the BBB (see for review Leybaert, 2005) an increase in: (i) the number of GLUT1; (ii) the intrinsic activity of the GLUT1; and/or (iii) the glucose concentration gradient over the barrier, thereby stimulating the driving force for glucose movement. It is possible that in metabolic disorders, these three mechanisms are not altered all together or at the same time. In the present study, the OB [Gluc] ECF stability observed in $f a / f a$ rats could be the result of the modulation of either GLUT1 expression or intrinsic activity at the BBB. In future experiments, it will be 
interesting to study more precisely these different mechanisms of glucose transport through the BBB during the different steps of feeding state in the OB of $f a / f a$ and $f a l+$ Zucker rats.

\section{OBESE fa/fa ZUCKER RATS HAVE A HIGHER OLFACTORY SENSITIVITY THAN LEAN $\mathrm{fa} /+$ RATS}

In the present study, Zucker fa/fa rats demonstrated a better olfactory sensitivity than Zucker $f a /+$ rats. This finding is supported by several recent studies. Thanos and collaborators demonstrated that $f a / f a$ Zucker rats displayed altered brain metabolic responses to food olfactory stimuli in several brain regions (Thanos et al., 2008). The same group also demonstrated that olfactory cues for a high-fat food stimulus elicit heightened behavioral responses in the obese Zucker $f a / f a$ rat compared to lean Zucker $f a /+$ rats (Thanos et al., 2013). Interestingly, obese ob/ob mice (unable to produce leptin) and $\mathrm{db} / \mathrm{db}$ mice (carrying a random mutation in the leptin receptor gene) are able to locate a hidden food reward based on olfactory cues, much faster than control mice. Several metabolic dysfunctions could explain the heightened olfactory perception of obese rats. As previously proposed, leptin is likely to mediate these responses (Thanos et al., 2013). Indeed, fa/fa rats are insensitive to leptin, an anorectic signal known to decrease olfactory sensitivity (Julliard et al., 2007; Aimé et al., 2012). The $f a$ mutation of the Zucker rat $(f a / f a)$ affects the leptin receptor gene and prevents the long form of the receptor $(\mathrm{Ob}-\mathrm{Rb})$ from being expressed (Chua et al., 1996). The Ob-Rb form of the receptor is expressed in the brain (Mercer et al., 1996; Fei et al., 1997) and is present at different levels of the olfactory system, including the OB (Shioda et al., 1998; Getchell et al., 2006; Baly et al., 2007; Prud'homme et al., 2009). Previous reports have demonstrated that leptin is able to modulate olfactory behavior as well as neuronal activity (Getchell et al., 2006; Julliard et al., 2007; Prud'homme et al., 2009; Savigner et al., 2009). Indeed, ICV administration of leptin decreases the expression of the activation marker c-fos in mitral and granular OB neurons (Prud'homme et al., 2009). Consistent with these studies, in a previous report, we found that ICV administration of leptin decreases the olfactory sensitivity of fasted animals to the level of satiated ones (Julliard et al., 2007). Here, we demonstrated that Zucker fa/fa rat, expressing a non-functional form of the leptin receptor, display a better olfactory sensitivity than the Zucker fa/+ rats, consistent with the aforementioned reports showing that leptin is responsible for a decrease in olfactory abilities.

Other metabolic dysfunctions could contribute to increase the olfactory perception of obese rats. The level of orexigenic peptides such as neuropeptide $\mathrm{Y}$, ghrelin and orexin A is upregulated in the hypothalamus of obese Zucker rats (Beck et al., 1990, 2003; Sanacora et al., 1990; Mondal et al., 1999) and ghrelin and orexin A are known to increase olfactory sensitivity (Julliard et al., 2007; Tong et al., 2011). Zucker fa/fa rats are also insensitive to the anorectic action of CCK (McLaughlin and Baile, 1980); and the expression level of proopiomelanocortin (POMC), the precursor of the anorectic neuroptide $\alpha \mathrm{MSH}$, is decreased in the arcuate nucleus of $f a / f a$ rats (Yamamoto et al., 2002). Although peripheral insulin injection induced similar fluctuations of $\mathrm{OB}$ [Gluc $]_{\mathrm{ECF}}$ in $f a / f a$ and $f a /+$ Zucker rats, peripheral glucose injection affected $\mathrm{OB}[\mathrm{Gluc}]_{\mathrm{ECF}}$ differentially in lean and obese Zucker rats. A peripheral glucose injection induced a greater increase of $\mathrm{OB}$ [Gluc] $]_{\mathrm{ECF}}$ in the OB of Zucker $\mathrm{fa} /+$ rats, compared to Zucker $f a / f a$ rats. This result is supported by a recent report that found no significant difference of brain glucose levels in obese Zucker rats after glucose injection compared to fasting brain glucose levels (Liistro et al., 2010). The brain of obese animals is chronically overexposed to glucose (even during fasting), as a consequence, it seems no more able to respond to physiologic glucose fluctuations. Importantly, the alteration of the molecular markers of glucose-sensing (up-regulation of SGLT1 expression and a probable alteration of GLUT4 trafficking) could also participate to the differences of olfactory detection observed between the two genotypes. Indeed, both SGLT1 and GLUT4 have been shown to be involved in neuronal glucose-sensing (McEwen and Reagan, 2004; O’Malley et al., 2006; Yu et al., 2013). This sensitivity for glucose is observed in specialized neurons located in numerous brain regions involved directly or indirectly in homeostasis control (for review see Routh, 2010; Levin et al., 2011), including the OB (Tucker et al., 2010, 2013). In the OB, the mitral cells have recently been demonstrated to be glucose sensitive (Tucker et al., $2010,2013)$ therefore glucose signaling could participate to the modulation of the olfactory sensitivity. Glucose-sensing neurons adapt their mean firing rate to the local fluctuations of extracellular glucose levels (González et al., 2008; McCrimmon, 2008). It is well-known that glucose-sensing is altered in the hypothalamus of obese animals (Rowe et al., 1996; Spanswick et al., 1997, 2000), and alteration of glucose-sensing in the olfactory system could play a role in the modulation of olfactory sensitivity observed in $f a / f a$ rats. Altogether, Zucker fa/fa rats overexpress orexigenic peptides known to increase olfactory sensitivity (Julliard et al., 2007; Tong et al., 2011) and are insensitive to anorectic signals known to decrease olfactory sensitivity (Julliard et al., 2007; Aimé et al., 2012) and they present an altered glucose-sensing in the OB. This imbalance in nutrient sensing, in orexigenic and anorectic signals is likely to account for the increase of olfactory sensitivity demonstrated here by the Zucker fa/fa rats. However in the present study, it remains difficult to decipher the respective role of obesity and of glucose-sensing alteration related to hyperglycemia on olfactory sensitivity. In order to go further, it will be intriguing to study olfactory sensitivity and expression of glucose-sensing genes on female Zucker rats because numerous gender-related metabolic differences exist in peripheral (Clark et al., 1983; Corsetti et al., 2000; Gustavsson et al., 2011) as well as in central tissues (Bogacka et al., 2004). Indeed, females develop obesity and insulin resistance but remain normoglycemic (Clark et al., 1983; Corsetti et al., 2000) and express differently glucosesensing genes in hypothalamus compared to males (Bogacka et al., 2004).

\section{CONCLUSION}

The whole of these data indicate that obese Zucker fa/fa rats demonstrate marked glucose intolerance and an alteration in the expression of glucose-sensing markers in the $\mathrm{OB}$. These newly found impairments, along with the well-described multiple metabolic dysfunctions of obese Zucker fa/fa rats modulate the processing of olfactory information and contribute to increase the olfactory sensitivity. Ultimately, changes in olfactory sensitivity 
participate in the hyperphagia and food-related disorder characteristic of the Zucker fa/fa rat.

\section{AUTHORS CONTRIBUTIONS}

All experiments were performed in the Centre de Recherche en Neurosciences de Lyon (CRNL). Inserm U1028-CNRS 5292UCBL1, Team-Olfaction: From Coding to Memory, Lyon, France. Pascaline Aimé and A. Karyn Julliard were responsible for the conception and design of the experiments; Pascaline Aimé, Rita Salem, Caroline Romestaing, Dolly Al Koborssy and Claude Duchamp were responsible for the collection of the data; Pascaline Aimé, Brigitte Palouzier-Paulignan, Rita Salem and A. Karyn Julliard were responsible for data analysis and interpretation; and Samuel Garcia designed the software used in analysis. Pascaline Aimé, Brigitte Palouzier-Paulignan, Claude Duchamp and A. Karyn Julliard drafted the article and revised it critically for important intellectual content. All authors approved the final version of the manuscript.

\section{ACKNOWLEDGMENTS}

This work was supported by Agence Nationale de la Recherche Grant ANR-05-PNRA 1E07 Aromalim, by the Ministère de la recherche et des nouvelles technologies, by the Centre National de la Recherche (CNRS) and the Claude Bernard University of Lyon (University Lyon1). We would like to thank the staff of the Neurochem facility (Université Claude-Bernard-Lyon I, 69373 Lyon Cedex 08, France), Anne Meiller for the engineering of the glucose biosensors.

\section{REFERENCES}

Aimé, P., Duchamp-Viret, P., Chaput, M. A., Savigner, A., Mahfouz, M., and Julliard, A. K. (2007). Fasting increases and satiation decreases olfactory detection for a neutral odor in rats. Behav. Brain Res. 179, 258-264. doi: 10.1016/j. bbr.2007.02.012

Aimé, P., Hegoburu, C., Jaillard, T., Degletagne, C., Garcia, S., Messaoudi, B., et al. (2012). A physiological increase of insulin in the olfactory bulb decreases detection of a learned aversive odor and abolishes food odor-induced sniffing behavior in rats. PLoS One 7:e51227. doi: 10.1371/journal.pone.00 51227

Allen Institute for Brain Science. (2010). Allen Brain Atlas. Seattle,WA, USA: Allen Institute for Brain Science Available online at: http://www.brain-map.org/

Alquier, T., Leloup, C., Lorsignol, A., and Pénicaud, L. (2006). Translocable glucose transporters in the brain: where are we in 2006? Diabetes 55, S131-S138. doi: 10. 2337/db06-s021

Amessou, M., Tahiri, K., Chauvet, G., and Desbuquois, B. (2010). Age-related changes in insulin receptor mRNA and protein expression in genetically obese Zucker rats. Diabetes Metab. 36, 120-128. doi: 10.1016/j.diabet.2009. 09.004

Apweiler, R., and Freund, P. (1993). Development of glucose intolerance in obese (fa/fa) Zucker rats. Horm. Metab. Res. 25, 521-524. doi: 10.1055/s-2007-10 02165

Baly, C., Aioun, J., Badonnel, K., Lacroix, M. C., Durieux, D., Schlegel, C., et al. (2007). Leptin and its receptors are present in the rat olfactory mucosa and modulated by the nutritional status. Brain Res. 1129, 130-141. doi: 10.1016/j. brainres.2006.10.030

Banks, W. A. (2004). The source of cerebral insulin. Eur. J. Pharmacol. 490, 5-12. doi: 10.1016/j.ejphar.2004.02.040

Banks, W. A. (2006). Blood-brain barrier and energy balance. Obesity (Silver Spring) 14(Suppl. 5), 234S-237S. doi: 10.1038/oby.2006.315

Banks, W. A., Jaspan, J. B., and Kastin, A. J. (1997). Selective, physiological transport of insulin across the blood-brain barrier: novel demonstration by species-specific radioimmunoassays. Peptides 18, 1257-1262. doi: 10. 1016/s0196-9781(97)00198-8
Baskin, D. G., Porte, D. Jr., Guest, K., and Dorsa, D. M. (1983). Regional concentrations of insulin in the rat brain. Endocrinology 112, 898-903. doi: 10.1210/endo112-3-898

Baskin, D. G., Stein, L. J., Ikeda, H., Woods, S. C., Figlewicz, D. P., Porte, D. Jr., et al. (1985). Genetically obese Zucker rats have abnormally low brain insulin content. Life Sci. 36, 627-633. doi: 10.1016/0024-3205(85)90166-3

Beck, B. (2000). Neuropeptides and obesity. Nutrition 16, 916-923. doi: 10. 1016/S0899-9007(00)00410-X

Beck, B., Burlet, A., Nicolas, J. P., and Burlet, C. (1990). Hypothalamic neuropeptide Y (NPY) in obese Zucker rats: implications in feeding and sexual behaviors. Physiol. Behav. 47, 449-453. doi: 10.1016/0031-9384(90)90107-f

Beck, B., Richy, S., and Stricker-Krongrad, A. (2003). Ghrelin and body weight regulation in the obese Zucker rat in relation to feeding state and dark/light cycle. Exp. Biol. Med. (Maywood) 228, 1124-1131.

Bogacka, I., Roane, D. S., Xi, X., Zhou, J., Li, B., Ryan, D. H., et al. (2004). Expression levels of genes likely involved in glucose-sensing in the obese Zucker rat brain. Nutr. Neurosci. 7, 67-74. doi: 10.1080/10284150410001710401

Bowlby, M. R., Fadool, D. A., Holmes, T. C., and Levitan, I. B. (1997). Modulation of the Kv1.3 potassium channel by receptor tyrosine kinases. J. Gen. Physiol. 110, 601-610. doi: 10.1085/jgp.110.5.601

Bradbury, M. W. (1993). The blood-brain barrier. Exp. Physiol. 78, 453-472.

Bray, G. A. (1977). The Zucker-fatty rat: a review. Fed. Proc. 36, 148-153.

Burguera, B., Couce, M. E., Long, J., Lamsam, J., Laakso, K., Jensen, M. D., et al. (2000). The long form of the leptin receptor (OB-Rb) is widely expressed in the human brain. Neuroendocrinology 71, 187-195. doi: 10.1159/000054536

Chaigneau, E., Tiret, P., Lecoq, J., Ducros, M., Knöpfel, T., and Charpak, S. (2007). The relationship between blood flow and neuronal activity in the rodent olfactory bulb. J. Neurosci. 27, 6452-6460. doi: 10.1523/jneurosci.3141-06.2007

Chua, S. C. Jr., Chung, W. K., Wu-Peng, X. S., Zhang, Y., Liu, S. M., Tartaglia, L., et al. (1996). Phenotypes of mouse diabetes and rat fatty due to mutations in the OB (leptin) receptor. Science 271, 994-996. doi: 10.1126/science.271.5251.994

Clark, J. B., Palmer, C. J., and Shaw, W. N. (1983). The diabetic Zucker fatty rat. Proc. Soc. Exp. Biol. Med. 173, 68-75. doi: 10.3181/00379727-173-41611

Colombani, A. L., Carneiro, L., Benani, A., Galinier, A., Jaillard, T., Duparc, T., et al. (2009). Enhanced hypothalamic glucose sensing in obesity: alteration of redox signaling. Diabetes 58, 2189-2197. doi: 10.2337/db09-0110

Corsetti, J. P., Sparks, J. D., Peterson, R. G., Smith, R. L., and Sparks, C. E. (2000). Effect of dietary fat on the development of non-insulin dependent diabetes mellitus in obese Zucker diabetic fatty male and female rats. Atherosclerosis 148, 231-241. doi: 10.1016/s0021-9150(99)00265-8

Doyle, P., Rohner-Jeanrenaud, F., and Jeanrenaud, B. (1993). Local cerebral glucose utilization in brains of lean and genetically obese (fa/fa) rats. Am. J. Physiol. 264 , E29-E36.

Dyer, J., Wood, I. S., Palejwala, A., Ellis, A., and Shirazi-Beechey, S. P. (2002). Expression of monosaccharide transporters in intestine of diabetic humans. Am. J. Physiol. Gastrointest. Liver Physiol. 282, G241-G248. doi: 10.1152/ajpgi.00310. 2001

Elfeber, K., Köhler, A., Lutzenburg, M., Osswald, C., Galla, H. J., Witte, O. W., et al. (2004). Localization of the Na+-D-glucose cotransporter SGLT1 in the bloodbrain barrier. Histochem. Cell Biol. 121, 201-207. doi: 10.1007/s00418-0040633-9

El Messari, S., Leloup, C., Quignon, M., Brisorgueil, M. J., Penicaud, L., and Arluison, M. (1998). Immunocytochemical localization of the insulin-responsive glucose transporter 4 (Glut4) in the rat central nervous system. J. Comp. Neurol. 399, 492-512. doi: 10.1002/(sici)10969861(19981005)399:4<492::aid-cne4>3.0.co;2-x

Fadool, D. A., Tucker, K., Phillips, J. J., and Simmen, J. A. (2000). Brain insulin receptor causes activity-dependent current suppression in the olfactory bulb through multiple phosphorylation of Kv1.3. J. Neurophysiol. 83, 2332-2348.

Fei, H., Okano, H. J., Li, C., Lee, G. H., Zhao, C., Darnell, R., et al. (1997). Anatomic localization of alternatively spliced leptin receptors (Ob-R) in mouse brain and other tissues. Proc. Natl. Acad. Sci. U S A 94, 7001-7005. doi: 10.1073/pnas.94. 13.7001

Ferraris, R. P., and Vinnakota, R. R. (1995). Intestinal nutrient transport in genetically obese mice. Am. J. Clin. Nutr. 62, 540-546.

Figlewicz, D. P., Dorsa, D. M., Stein, L. J., Baskin, D. G., Paquette, T., Greenwood, M. R., et al. (1985). Brain and liver insulin binding is decreased in Zucker rats carrying the 'fa' gene. Endocrinology 117, 1537-1543. doi: 10.1210/endo-117-41537 
Getchell, T. V., Kwong, K., Saunders, C. P., Stromberg, A. J., and Getchell, M. L. (2006). Leptin regulates olfactory-mediated behavior in ob/ob mice. Physiol. Behav. 87, 848-856. doi: 10.1016/j.physbeh.2005.11.016

González, J. A., Jensen, L. T., Fugger, L., and Burdakov, D. (2008). Metabolismindependent sugar sensing in central orexin neurons. Diabetes 57, 2569-2576. doi: $10.2337 / \mathrm{db} 08-0548$

Guerre-Millo, M. (1997). Regulation of ob gene and overexpression in obesity. Biomed. Pharmacother. 51, 318-323. doi: 10.1016/s0753-3322(97)88048-1

Gustavsson, C., Soga, T., Wahlström, E., Vesterlund, M., Azimi, A., Norstedt, G., et al. (2011). Sex-dependent hepatic transcripts and metabolites in the development of glucose intolerance and insulin resistance in Zucker diabetic fatty rats. J. Mol. Endocrinol. 47, 129-143. doi: 10.1530/jme-11-0007

Hill, J. M., Lesniak, M. A., Pert, C. B., and Roth, J. (1986). Autoradiographic localization of insulin receptors in rat brain: prominence in olfactory and limbic areas. Neuroscience 17, 1127-1138. doi: 10.1016/0306-4522(86)90082-5

Ikeda, H., Nishikawa, K., and Matsuo, T. (1980). Feeding responses of Zucker fatty rat to 2-deoxy-D-glucose, norepinephrine and insulin. Am. J. Physiol. 239, E379-E384.

Ikeda, H., West, D. B., Pustek, J. J., Figlewicz, D. P., Greenwood, M. R., Porte, D. Jr., et al. (1986). Intraventricular insulin reduces food intake and body weight of lean but not obese Zucker rats. Appetite 7, 381-386. doi: 10.1016/s01956663(86)80006-x

Julliard, A. K., Chaput, M. A., Apelbaum, A., Aimé, P., Mahfouz, M., and DuchampViret, P. (2007). Changes in rat olfactory detection performance induced by orexin and leptin mimicking fasting and satiation. Behav. Brain Res. 183, $123-$ 129. doi: 10.1016/j.bbr.2007.05.033

Julliard, A. K., and Hartmann, D. J. (1998). Spatiotemporal patterns of expression of extracellular matrix molecules in the developing and adult rat olfactory system. Neuroscience 84, 1135-1150. doi: 10.1016/s0306-4522(97) 00544-7

Kaul, L., and Berdanier, C. D. (1975). Effect of meal-feeding on the daily variations of insulin, glucose and NADP-linked dehydrogenases in rats. J. Nutr. 105, 11321140.

Kuczewski, N., Fourcaud-Trocmé, N., Savigner, A., Thevenet, M., Aimé, P., Garcia, S., et al. (2014). Insulin modulates network activity in olfactory bulb slices: impact on odour processing. J. Physiol. 592, 2751-2769. doi: 10.1113/jphysiol. 2013.269639

Levin, B. E., Magnan, C., Dunn-Meynell, A., and Le Foll, C. (2011). Metabolic sensing and the brain: who, what, where and how? Endocrinology 152, 25522557. doi: 10.1210/en.2011-0194

Leybaert, L. (2005). Neurobarrier coupling in the brain: a partner of neurovascular and neurometabolic coupling? J. Cereb. Blood Flow Metab. 25, 2-16. doi: 10 1038/sj.jcbfm.9600001

Liistro, T., Guiducci, L., Burchielli, S., Panetta, D., Belcari, N., Pardini, S., et al. (2010). Brain glucose overexposure and lack of acute metabolic flexibility in obesity and type 2 diabetes: a PET-[18F]FDG study in Zucker and ZDF rats. J. Cereb. Blood Flow Metab. 30, 895-899. doi: 10.1038/jcbfm.2010.27

Livingston, J. N., Unger, J. W., Moxley, R. T., and Moss, A. (1993). Phosphotyrosinecontaining proteins in the CNS of obese Zucker rats are decreased in the absence of changes in the insulin receptor. Neuroendocrinology 57, 481-488. doi: 10. $1159 / 000126395$

Magistretti, P. J., Pellerin, L., Rothman, D. L., and Shulman, R. G. (1999). Energy on demand. Science 283, 496-497. doi: 10.1126/science.283.5401.496

Marfaing-Jallat, P., Levacher, C., Calando, Y., Picon, L., and Penicaud, L. (1992). Glucose utilization and insulin binding in discrete brain areas of obese rats. Physiol. Behav. 52, 713-716. doi: 10.1016/0031-9384(92)90402-n

Marks, J. L., and Eastman, C. J. (1989). Effect of starvation on insulin receptors in rat brain. Neuroscience 30, 551-556. doi: 10.1016/0306-4522(89) 90272-8

Marks, J. L., Porte, D. Jr., Stahl, W. L., and Baskin, D. G. (1990). Localization of insulin receptor mRNA in rat brain by in situ hybridization. Endocrinology 127, 3234-3236. doi: 10.1210/endo-127-6-3234

Martin, R. J., Wangsness, P. J., and Gahagan, J. H. (1978). Diurnal changes in serum metabolites and hormones in lean and obese Zucker rats. Horm. Metab. Res. 10, 187-192. doi: 10.1055/s-0028-1093431

McCrimmon, R. (2008). The mechanisms that underlie glucose sensing during hypoglycaemia in diabetes. Diabet. Med. 25, 513-522. doi: 10.1111/j.1464-5491. 2008.02376.x
McEwen, B. S., and Reagan, L. P. (2004). Glucose transporter expression in the central nervous system: relationship to synaptic function. Eur. J. Pharmacol. 490, 13-24. doi: 10.1016/j.ejphar.2004.02.041

McLaughlin, C. L., and Baile, C. A. (1980). Decreased sensitivity of Zucker obese rats to the putative satiety agent cholecystokinin. Physiol. Behav. 25, 543-548. doi: 10.1016/0031-9384(80)90119-5

McNay, E. C., and Gold, P. E. (1999). Extracellular glucose concentrations in the rat hippocampus measured by zero-net-flux: effects of microdialysis flow rate, strain and age. J. Neurochem. 72, 785-790. doi: 10.1046/j.1471-4159.1999. 0720785.x

McNay, E. C., McCarty, R. C., and Gold, P. E. (2001). Fluctuations in brain glucose concentration during behavioral testing: dissociations between brain areas and between brain and blood. Neurobiol. Learn. Mem. 75, 325-337. doi: 10. 1006/nlme.2000.3976

Melnyk, R. B. (1987). Decreased binding to hypothalamic insulin receptors in young genetically obese rats. Physiol. Behav. 40, 237-241. doi: 10.1016/00319384(87)90213-7

Mercer, J. G., Hoggard, N., Williams, L. M., Lawrence, C. B., Hannah, L. T., and Trayhurn, P. (1996). Localization of leptin receptor mRNA and the long form splice variant $(\mathrm{Ob}-\mathrm{Rb})$ in mouse hypothalamus and adjacent brain regions by in situ hybridization. FEBS Lett. 387, 113-116. doi: 10.1016/0014-5793(96) 00473-5

Mondal, M. S., Nakazato, M., Date, Y., Murakami, N., Hanada, R., Sakata, T., et al. (1999). Characterization of orexin-A and orexin-B in the microdissected rat brain nuclei and their contents in two obese rat models. Neurosci. Lett. 273, 4548. doi: 10.1016/s0304-3940(99)00624-2

Morton, A. P., and Hanson, P. J. (1984). Monosaccharide transport by the small intestine of lean and genetically obese (ob/ob) mice. Q. J. Exp. Physiol. 69, 117126.

Nawroth, J. C., Greer, C. A., Chen, W. R., Laughlin, S. B., and Shepherd, G. M. (2007). An energy budget for the olfactory glomerulus. J. Neurosci. 27, 97909800. doi: 10.1523/jneurosci.1415-07.2007

O'Malley, D., Reimann, F., Simpson, A. K., and Gribble, F. M. (2006). Sodiumcoupled glucose cotransporters contribute to hypothalamic glucose sensing. Diabetes 55, 3381-3386. doi: 10.2337/db06-0531

Osswald, C., Baumgarten, K., Stümpel, F., Gorboulev, V., Akimjanova, M., Knobeloch, K. P., et al. (2005). Mice without the regulator gene RsclAl exhibit increased $\mathrm{Na}+-\mathrm{D}$-glucose cotransport in small intestine and develop obesity. Mol. Cell. Biol. 25, 78-87. doi: 10.1128/mcb.25.1.78-87.2005

Palouzier-Paulignan, B., Lacroix, M. C., Aimé, P., Baly, C., Caillol, M., Congar, P., et al. (2012). Olfaction under metabolic influences. Chem. Senses 37, 769-797. doi: 10.1093/chemse/bjs059

Paxinos, G., and Watson, C. (2007). The Rat Brain in Stereotaxic Coordinates. San Diego: Academic Press.

Pénicaud, L., Ferré, P., Terretaz, J., Kinebanyan, M. F., Leturque, A., Doré, E., et al. (1987). Development of obesity in Zucker rats. Early insulin resistance in muscles but normal sensitivity in white adipose tissue. Diabetes 36, 626-631. doi: 10.2337/diabetes.36.5.626

Peyron, C., Tighe, D. K., van den Pol, A. N., de Lecea, L., Heller, H. C., Sutcliffe, J. G., et al. (1998). Neurons containing hypocretin (orexin) project to multiple neuronal systems. J. Neurosci. 18, 9996-10015.

Poppe, R., Karbach, U., Gambaryan, S., Wiesinger, H., Lutzenburg, M., Kraemer, M., et al. (1997). Expression of the Na+-D-glucose cotransporter SGLT1 in neurons. J. Neurochem. 69, 84-94. doi: 10.1046/j.1471-4159.1997.69010084.x

Prud'homme, M. J., Lacroix, M. C., Badonnel, K., Gougis, S., Baly, C., Salesse, R., et al. (2009). Nutritional status modulates behavioural and olfactory bulb Fos responses to isoamyl acetate or food odour in rats: roles of orexins and leptin. Neuroscience 162, 1287-1298. doi: 10.1016/j.neuroscience.2009. 05.043

Routh, V. H. (2010). Glucose sensing neurons in the ventromedial hypothalamus. Sensors (Basel) 10, 9002-9025. doi: 10.3390/s101009002

Rowe, I. C., Boden, P. R., and Ashford, M. L. (1996). Potassium channel dysfunction in hypothalamic glucose-receptive neurones of obese Zucker rats. J. Physiol. 497(Pt. 2), 365-377.

Sanacora, G., Kershaw, M., Finkelstein, J. A., and White, J. D. (1990). Increased hypothalamic content of preproneuropeptide Y messenger ribonucleic acid in genetically obese Zucker rats and its regulation by food deprivation. Endocrinology 127, 730-737. doi: 10.1210/endo-127-2-730 
Savigner, A., Duchamp-Viret, P., Grosmaitre, X., Chaput, M., Garcia, S., Ma, M., et al. (2009). Modulation of spontaneous and odorant-evoked activity of rat olfactory sensory neurons by two anorectic peptides, insulin and leptin. J. Neurophysiol. 101, 2898-2906. doi: 10.1152/jn.91169.2008

Schwartz, M. W., Sipols, A., Kahn, S. E., Lattemann, D. F., Taborsky, G. J. Jr., Bergman, R. N., et al. (1990). Kinetics and specificity of insulin uptake from plasma into cerebrospinal fluid. Am. J. Physiol. 259, E378-E383.

Shioda, S., Funahashi, H., Nakajo, S., Yada, T., Maruta, O., and Nakai, Y. (1998). Immunohistochemical localization of leptin receptor in the rat brain. Neurosci. Lett. 243, 41-44. doi: 10.1016/s0304-3940(98)00082-2

Sitren, H. S., and Stevenson, N. R. (1978). The effects of meal-feeding at different times of the day on daily changes in serum insulin, gastrin and liver enzymes in the rat. J. Nutr. 108, 1393-1401.

Slotnick, B. M., Westbrook, F., and Darling, F. M. C. (1997). What the rat's nose tells the rat's mouth: long delay aversion conditioning with aqueous odors and potentiation of tatse by odors. Anim. Learn. Behav. 25, 357-369. doi: 10. 3758/BF03199093

Sokal, R., and Rohlf, F. (1981). Biometry: The Principals and Practice of Statistics in Biological Research. San Francisco: Freeman, W.H.

Spanswick, D., Smith, M. A., Groppi, V. E., Logan, S. D., and Ashford, M. L. (1997). Leptin inhibits hypothalamic neurons by activation of ATP-sensitive potassium channels. Nature 390, 521-525. doi: 10.1038/37379

Spanswick, D., Smith, M. A., Mirshamsi, S., Routh, V. H., and Ashford, M. L. (2000). Insulin activates ATP-sensitive K+ channels in hypothalamic neurons of lean, but not obese rats. Nat. Neurosci. 3, 757-758. doi: 10.1038/77660

Stein, L. J., Dorsa, D. M., Baskin, D. G., Figlewicz, D. P., Ikeda, H., Frankmann, S. P., et al. (1983). Immunoreactive insulin levels are elevated in the cerebrospinal fluid of genetically obese Zucker rats. Endocrinology 113, 2299-2301. doi: 10. 1210/endo-113-6-2299

Strubbe, J. H., Porte, D. Jr., and Woods, S. C. (1988). Insulin responses and glucose levels in plasma and cerebrospinal fluid during fasting and refeeding in the rat. Physiol. Behav. 44, 205-208. doi: 10.1016/0031-9384(88)90139-4

Tabatabai, N. M., Sharma, M., Blumenthal, S. S., and Petering, D. H. (2009). Enhanced expressions of sodium-glucose cotransporters in the kidneys of diabetic Zucker rats. Diabetes Res. Clin. Pract. 83, e27-e30. doi: 10.1016/j.diabres. 2008.11.003

Tartaglia, L. A., Dembski, M., Weng, X., Deng, N., Culpepper, J., Devos, R., et al. (1995). Identification and expression cloning of a leptin receptor, OB-R. Cell 83, 1263-1271. doi: 10.1016/0092-8674(95)90151-5

Thanos, P. K., Michaelides, M., Gispert, J. D., Pascau, J., Soto-Montenegro, M. L., Desco, M., et al. (2008). Differences in response to food stimuli in a rat model of obesity: in-vivo assessment of brain glucose metabolism. Int. J. Obes. (Lond). 32, 1171-1179. doi: 10.1038/ijo.2008.50

Thanos, P. K., Robison, L. S., Robinson, J. K., Michaelides, M., Wang, G. J., and Volkow, N. D. (2013). Obese rats with deficient leptin signaling exhibit heightened sensitivity to olfactory food cues. Synapse 67, 171-178. doi: 10 . 1002/syn.21627

Tong, J., Mannea, E., Aimé, P., Pfluger, P. T., Yi, C. X., Castaneda, T. R., et al. (2011). Ghrelin enhances olfactory sensitivity and exploratory sniffing in rodents and humans. J. Neurosci. 31, 5841-5846. doi: 10.1523/JNEUROSCI.5680-10.2011

Tsujii, S., Nakai, Y., Takahashi, H., Usui, T., Koh, T., Yonekura, Y., et al. (1988). Effect of food deprivation on regional brain glucose utilization in lean and fatty Zucker rats. Brain Res. 475, 371-375. doi: 10.1016/0006-8993(88)90628-2

Tucker, K., Cavallin, M. A., Jean-Baptiste, P., Biju, K. C., Overton, J. M., Pedarzani, P., et al. (2010). The olfactory bulb: a metabolic sensor of brain insulin and glucose concentrations via a voltage-gated potassium channel. Results Probl. Cell Differ. 52, 147-157. doi: 10.1007/978-3-642-14426-4_12

Tucker, K., Cho, S., Thiebaud, N., Henderson, M. X., and Fadool, D. A. (2013). Glucose sensitivity of mouse olfactory bulb neurons is conveyed by a voltagegated potassium channel. J. Physiol. 591, 2541-2561. doi: 10.1113/jphysiol.2013. 254086

Ueno, M., Dobrogowska, D. H., and Vorbrodt, A. W. (1996). Immunocytochemical evaluation of the blood-brain barrier to endogenous albumin in the olfactory bulb and pons of senescence-accelerated mice (SAM). Histochem. Cell Biol. 105, 203-212. doi: 10.1007/bf01462293

Unger, J., McNeill, T. H., Moxley, R. T. 3rd, White, M., Moss, A., and Livingston, J. N. (1989). Distribution of insulin receptor-like immunoreactivity in the rat forebrain. Neuroscience 31, 143-157. doi: 10.1016/0306-4522(89) 90036-5
Vannucci, S. J., Koehler-Stec, E. M., Li, K., Reynolds, T. H., Clark, R., and Simpson, I. A. (1998). GLUT4 glucose transporter expression in rodent brain: effect of diabetes. Brain Res. 797, 1-11. doi: 10.1016/s0006-8993(98) 00103-6

Vasselli, J. R., Cleary, M. P., Jen, K. L., and Greenwood, M. R. (1980). Development of food motivated behavior in free feeding and food restricted Zucker fatty (fa/fa) rats. Physiol. Behav. 25, 565-573. doi: 10.1016/0031-9384(80) 90123-7

Vasylieva, N., Barnych, B., Meiller, A., Maucler, C., Pollegioni, L., Lin, J. S., et al. (2011). Covalent enzyme immobilization by poly(ethylene glycol) diglycidyl ether (PEGDE) for microelectrode biosensor preparation. Biosens. Bioelectron. 26, 3993-4000. doi: 10.1016/j.bios.2011.03.012

White, B. D., and Martin, R. J. (1997). Evidence for a central mechanism of obesity in the Zucker rat: role of neuropeptide Y and leptin. Proc. Soc. Exp. Biol. Med. 214, 222-232. doi: 10.3181/00379727-214-44090

Wilcox, B. J., Corp, E. S., Dorsa, D. M., Figlewicz, D. P., Greenwood, M. R., Woods, S. C., et al. (1989). Insulin binding in the hypothalamus of lean and genetically obese Zucker rats. Peptides 10, 1159-1164. doi: 10.1016/0196-9781(89) 90008-9

Winocur, G., Greenwood, C. E., Piroli, G. G., Grillo, C. A., Reznikov, L. R., Reagan, L. P., et al. (2005). Memory impairment in obese Zucker rats: an investigation of cognitive function in an animal model of insulin resistance and obesity. Behav. Neurosci. 119, 1389-1395. doi: 10.1037/0735-7044.119.5.1389

Woods, S. C., Seeley, R. J., Baskin, D. G., and Schwartz, M. W. (2003). Insulin and the blood-brain barrier. Curr. Pharm. Des. 9, 795-800. doi: 10. 2174/1381612033455323

Yamamoto, Y., Ueta, Y., Yamashita, H., Asayama, K., and Shirahata, A. (2002). Expressions of the prepro-orexin and orexin type 2 receptor genes in obese rat. Peptides 23, 1689-1696. doi: 10.1016/s0196-9781(02)00111-0

Yamashita, T., Murakami, T., Iida, M., Kuwajima, M., and Shima, K. (1997). Leptin receptor of Zucker fatty rat performs reduced signal transduction. Diabetes 46, 1077-1080. doi: 10.2337/diabetes.46.6.1077

Yang, X., Renken, R., Hyder, F., Siddeek, M., Greer, C. A., Shepherd, G. M., et al. (1998). Dynamic mapping at the laminar level of odor-elicited responses in rat olfactory bulb by functional MRI. Proc. Natl. Acad. Sci. U S A 95, 7715-7720. doi: 10.1073/pnas.95.13.7715

Yu, A. S., Hirayama, B. A., Timbol, G., Liu, J., Basarah, E., Kepe, V., et al. (2010). Functional expression of SGLTs in rat brain. Am. J. Physiol. Cell Physiol. 299, C1277-C1284. doi: 10.1152/ajpcell.00296.2010

Yu, A. S., Hirayama, B. A., Timbol, G., Liu, J., Diez-Sampedro, A., Kepe, V., et al. (2013). Regional distribution of SGLT activity in rat brain in vivo. Am. J. Physiol. Cell Physiol. 304, C240-C247. doi: 10.1152/ajpcell.00317.2012

Zarjevski, N., Doyle, P., and Jeanrenaud, B. (1992). Muscle insulin resistance may not be a primary etiological factor in the genetically obese fa/fa rat. Endocrinology 130, 1564-1570. doi: 10.1210/en.130.3.1564

Zhu, M., Nehra, D., Ackerman, J. J., and Yablonskiy, D. A. (2004). On the role of anesthesia on the body/brain temperature differential in rats. J. Therm. Biol. 29, 599-603. doi: 10.1016/j.jtherbio.2004.08.029

Zucker, L. M., and Antoniades, H. N. (1972). Insulin and obesity in the Zucker genetically obese rat "fatty". Endocrinology 90, 1320-1330. doi: 10.1210/endo90-5-1320

Conflict of Interest Statement: The authors declare that the research was conducted in the absence of any commercial or financial relationships that could be construed as a potential conflict of interest.

Received: 15 April 2014; accepted: 01 September 2014; published online: 17 September 2014.

Citation: Aimé P, Palouzier-Paulignan B, Salem R, Al Koborssy D, Garcia S, Duchamp $C$, Romestaing $C$ and Julliard $A K$ (2014) Modulation of olfactory sensitivity and glucose-sensing by the feeding state in obese Zucker rats. Front. Behav. Neurosci. 8:326. doi: 10.3389/fnbeh.2014.00326

This article was submitted to the journal Frontiers in Behavioral Neuroscience.

Copyright (C) 2014 Aimé, Palouzier-Paulignan, Salem, Al Koborssy, Garcia, Duchamp, Romestaing and Julliard. This is an open-access article distributed under the terms of the Creative Commons Attribution License (CC BY). The use, distribution or reproduction in other forums is permitted, provided the original author(s) or licensor are credited and that the original publication in this journal is cited, in accordance with accepted academic practice. No use, distribution or reproduction is permitted which does not comply with these terms. 